$1 \quad$ New data on flatfish scuticociliatosis reveal

4 ANA-PAULA DEFELIPE ${ }^{1}$, JESÚS LAMAS ${ }^{2}$, ROSA-ANA SUEIRO $^{1,2}$,

5 IRIA FOLGUEIRA ${ }^{1}$ and JOSÉ-MANUEL LEIRO ${ }^{1 *}$

$6{ }^{1}$ Departamento de Microbiología y Parasitología, Instituto de Investigación y Análisis Alimentarios,

$7 \quad$ Universidad de Santiago de Compostela, 15782 Santiago de Compostela, Spain

$8{ }^{2}$ Departamento de Biología Celular y Ecología, Instituto de Acuicultura, Universidad de Santiago de

9 Compostela, 15782 Santiago de Compostela, Spain

SHORT TITLE: Scuticociliatosis in flatfish

\title{
$21{ }^{*}$ Correspondence
}

22 José M. Leiro, Laboratorio de Parasitología, Instituto de Investigación y Análisis Alimentarios, 23 c/ Constantino Candeira s/n, 15782, Santiago de Compostela (A Coruña), Spain; Tel: 24 34981563100; Fax: 34881816070; E-mail: josemanuel.leiro@usc.es 


\section{SUMMARY}

26 Scuticociliatosis is a severe disease in farmed flatfish. However, the causative agent is 27 not always accurately identified. In this study, we identified two isolates of 28 scuticociliates from an outbreak in cultured fine flounder Paralichthys adspersus. 29 Scuticociliate identification was based on morphological data, examination of life stages 30 and the use of molecular approaches. The isolates were compared with a strain of 31 Philasterides dicentrachi from turbot Scophthalmus maximus and with a strain 32 deposited in the American Type Culture Collection as Miamiensis avidus ATCC $^{\circledR}$ $3350180^{\mathrm{TM}}$. The use of morphological, biological, and molecular methods enabled us to 34 identify the isolates from the fine flouder as $P$. dicentrarchi. Comparison of $P$. 35 dicentrachi isolates and $M$. avidus revealed some differences in the buccal apparatus. 36 Unlike $P$. dicentrarchi, $M$. avidus has a life cycle with three forms: macrostomes 37 (capable of feeding on P. dicentrarchi), microstomes, and tomites. Additionally, we 38 found differences in the $18 \mathrm{~S}$ rRNA and $\alpha$ - and $\beta$-tubulin gene sequences, indicating that 39 P. dicentrarchi and M. avidus are different species. We therefore reject the synonymy / 40 conspecificity of the two taxa previously suggested. Finally, we suggest that a 41 combination of morphological, biological, molecular (by multigene analysis), and 42 serological techniques could improve the identification of scuticociliates parasites in 43 fish.

45 Key words:

46 Paralichthys adspersus; Scophthalmus maximus; scuticociliates; SSUrRNA gene; $\alpha$ - $\beta$ 47 tubulin gene. 


\section{INTRODUCTION}

51 Scuticociliatosis is a parasitic disease caused by around 20 species of ciliates

52 included in the subclass Scuticociliatia Small, 1967. The ciliates are common free-living

53 members of limnetic and marine ecosystems and can transform into histiophagous

54 parasites that cause serious infections in some aquatic animals (Kim et al. 2004a;

55 Harikrishnan et al. 2010; Fan et al. 2011; Pan et al. 2013). Scuticociliates can infect a

56 wide variety of teleost fish species: the European seabass Dicentrarchus labrax

57 (Linnaeus, 1758) (Dragesco et al. 1995; Ramos et al. 2007); the Southern bluefin tuna

58 Thunnus maccoyii (Castelnau, 1872) (Munday et al. 1997); the silver pomfret Pampus

59 argenteus (Euphrasen, 1788) (Azad et al. 2007); the black rockfish Sebastes schlegelii

60 Hilgendorf, 1880 (Whang et al. 2013); hatchery-reared juveniles of the Hapuku

61 wreckfish Polyprion oxygeneios (Schneider \& Forster, 1801) and adult kingfish Seriola

62 lalandi Valenciennes, 1833 (Smith et al. 2009); the sea dragons Phylloopteryx

63 taeniolatus (Lacepède, 1804) and Phycodurus eques (Günther, 1865) (Umehara et al.

64 2003; Rossteuscher et al. 2008; Bonar et al. 2013); the seahorses Hippocampus erectus

65 Perry, 1810, H. kuda Bleeker,1852, H. abdominalis Lesson, 1872, and H. hippocampus

66 (Linnaeus, 1758) (Thompson \& Moewus 1964; Shin et al. 2011; di Cicco et al. 2013;

67 Declercq et al. 2014; Ofelio et al. 2014); and elasmobranch fish such as the zebra shark

68 Stegostoma fasciatum Hermann, 1783, the shark of Port Jackson Heterodontus

69 portusjacksoni Meyer, 1793, and the Japanese bullhead shark H.japonicus Micklouho-

70 MaClay and MacLeay, 1884 (Stidworthy et al. 2014). Scuticociliates also can colonize

71 crustaceans and echinoderms, acting either as parasites or commensals (Small et al.

72 2005; Lynn \& Strüder-Kypke 2005). One of the major problems in diagnosing fish

73 scuticociliatosis is the difficulty in identifying the pathogenic species causing the

74 disease. Although morphological and morphogenetic characters of the ciliary pattern 
75 are routinely identified by using various silver impregnation methods, the systematic 76 positions of certain taxa remain ambiguous and their characteristics must be reviewed so 77 that species can be correctly identified (Jung et al. 2005; Miao et al. 2008; Gao et al. 78 2013). Biochemical, molecular, and immunological techniques must be accompanied by 79 conventional morphological studies based on light microscopic analyses of live and 80 silver-stained material for the correct identification of scuticociliate species, as well as 81 for the reconstruction of the phylogenetic relationships and the analysis of the 82 instraspecific variation between strains (Budiño et al. 2011a, 2012; Pan et al. 2013).

83 Many scuticociliates, especially species of the genera Pseudocohnilembus Evans 84 and Thompson, 1964, Uronema Dujardin, 1841, Miamiensis Thompson and Moewus, 85 1964, and Philasterides Kahl, 1926, have been associated with infections in flatfish. 86 Such infections seriously affect culture of the turbot Scophthalmus maximus (Linnaeus, 87 1758) and the olive flounder Paralichthys olivaceus (Temminck \& Schlegel, 1846), 88 causing high mortalities and economic losses on fish farms (Iglesias et al. 2001; Kim et 89 al. 2004a). Philasterides dicentrarchi Dragesco, Dragesco, Coste, Gasc, Romestand, 90 Raymond and Bouix, 1995 has been identified as the main aetiological agent of 91 scuticociliatosis in farmed turbot and olive flounder on the basis of morphological and 92 molecular criteria (Iglesias et al. 2001; Paramá et al. 2006; Kim et al. 2004a). Recently, 93 Jung et al. (2005) identified several specimens isolated from the olive flounder as 94 Miamiensis avidus Thompson \& Moewus, 1964, on the basis of morphological criteria. 95 Synonymy between these ciliate species was suggested after comparison of the 96 morphological characteristics and the SSUrRNA gene sequences of $M$. avidus and $P$. 97 dicentrarchi isolates (Jung et al. 2007). Hence, P. dicentrarchi is considered a junior 98 synonym of M. avidus (Song \& Wilbert 2000; Jung et al. 2007; Song et al. 2009a; Gao 99 et al. 2010; Budiño et al. 2011a). 
100 To date, identification and characterization of the species responsible for most 101 outbreaks of scuticociliatosis in turbot and olive flounder have been based on the 102 original morphological descriptions of $P$. dicentrarchi (Dragesco et al. 1995) and $M$. 103 avidus (Thompson \& Moewus, 1964), or on availabale data on nucleotide sequences of 104 ribosomal genes obtained by different authors in various ciliate strains isolated from 105 turbot (Paramá et al. 2006) and from olive flounder (Jung et al. 2011). However, 106 identification has never been made by comparing the nucleotide sequences of the 107 species $M$. avidus currently deposited in ATCC (M. avidus $\mathrm{ATCC}^{\circledR} 50180^{\mathrm{TM}}$ ). This 108 restricts the accurate identification of this species at the molecular level.

109 In this study, we (i) describe an outbreak of scuticociliatosis in fine flounder 110 Paralichthys adspersus (Steindachner, 1867) cultured in Peru and (ii) compare the 111 morphological and biometrical characteristics, SSUrRNA, $\alpha-$ and $\beta$-tubulin gene 112 sequences, antigenic relationships, tomitogenesis, and prey induced transformation in 113 ciliates isolated from the fine flounder, in the ciliate $P$. dicentrarchi isolated from turbot, 114 and in the ciliate species M. avidus $\mathrm{ATCC}^{\circledR} 50180^{\mathrm{TM}}$ (strain $\mathrm{Ma} / 2$ ). The results provide 115 new data that should be considered in the identification of the aetiological agents of 116 scuticociliatosis in flatfish.

117

118 MATERIAL AND METHODS

119 Animals and ethical approval

120 Twenty specimens of turbot Scophpthalmus maximus of approximately $50 \mathrm{~g}$ body 121 weight were obtained from a local fish farm (Galicia, NW Spain). The fish were 122 maintained in 50-1 closed-circuit aerated tanks at $17-18^{\circ} \mathrm{C}$. Ten ICR (Swiss) CD-1 mice 123 (between eight and ten weeks old) initially supplied by the Charles River Laboratories 124 (USA) were bred and maintained in the Central Animal Facility of the University of 
125 Santiago de Compostela (Spain). The mice were held according to the criteria of

126 protection, control, care and welfare of animals and the legislative requirements relating

127 to the use of animals for experimentation (EU Directive 86/609 / EEC), the Declaration

128 of Helsinki, and/or the Guide for the Care and Use of Laboratory Animals as adopted

129 and promulgated by the US National Institutes of Health (NIH Publication No. 85-23,

130 revised 1996). The Institutional Animal Care and Use Committee of the University of

131 Santiago de Compostela approved all experimental protocols.

133 Isolation, ciliate culture, and experimental infections

134 In 2014, an outbreak of scuticociliatosis affecting the fine flounder $P$. adspersus was 135 detected on a fish farm in Peru (Ancash, Huarmey Province). The farm was equipped 136 with two water flow systems: one with closed and the other with open recirculation.

137 Mortality was very high in both systems, affecting fish of different sizes. Outbreaks of 138 scuticociliatosis in fine flounder coincided with a series of anomalies in the seawater 139 temperature registered in the eastern Pacific region affected by El Niño resulting in an 140 average temperature that was $3.1{ }^{\circ} \mathrm{C}$ higher than the annual average (Comunicado

141 Oficial ENFEN - Estudio Nacional del Fenómeno El Niño-Nº9-2014, Instituto del Mar 142 del Perú -IMARPE). Ciliates were isolated from fish ranging from 16-27 $\mathrm{cm}$ in size 143 (Fig. 1A). Two isolates of the scuticociliates, denominated Pe5 and Pe7, were obtained 144 from ascitic fluid (with a concentration of approximately $5 \times 10^{6}$ trophozoites $/ \mathrm{ml}$ ) of 145 naturally infected specimens of the fine flounder P. adspersus.

146 Virulent strain I1 of $P$. dicentrarchi was originally isolated from ascites fluid 147 turbot from infected fish on a farm in Galicia (NW Spain) (Iglesias et al. 2001).

148 Strain $\mathrm{Ma} / 2$ of $M$. avidus deposited by A.T. Soldo and E. B. Small (Veterans 149 Administration Medical Center, Miami, FL) with the name Miamiensis avidus 
150 Thompson and Moewus (ATCC ${ }^{\circledR} 50180^{\mathrm{TM}}$ ) was acquired from the American Type

151 Culture Collection (ATCC, USA). The strain Ma/2 of M. avidus belonged to the

152 collection of Dr G.G. Holz and it was originally isolated by Dr L Moewus from infected 153 seahorses and cultivated axenically since 1963 (Moewus, 1963; Kaneshiro et al. 1969).

154 Isolates Pe5, Pe7, and P. dicentrarchi strain I1 were maintained in the laboratory

155 under the culture conditions described by Iglesias et al. (2003a). Strain Ma/2 of $M$. 156 avidus was cultivated axenically in ATCC $^{\circledR}$ medium 1651 MA (LGC Standards, Spain) 157 at $25^{\circ} \mathrm{C}$ and subcultured every 3-5 days.

158 For experimental infections, turbot were injected intraperitoneally with $0.1 \mathrm{ml}$ of $15910^{6}$ ciliates $/ \mathrm{ml}$ (M. avidus, strain Ma/2) in phosphate-buffered saline (PBS) containing $16010 \mathrm{mM} \mathrm{Na}_{2} \mathrm{HPO}_{4}, 2 \mathrm{mM} \mathrm{KH} \mathrm{KO}_{4}, 2.7 \mathrm{mM} \mathrm{KCl}$, and $137 \mathrm{mM} \mathrm{NaCl}$, as previously 161 described (Paramá et al. 2003), and the fish were observed daily for signs of infection 162 and mortality. Infection was confirmed post mortem by the presence of ciliates in 163 organs and tissues.

164

165 Morphological and histological analyses

166 Ciliates obtained at the exponential phase of culture (days 2-3) were concentrated by 167 centrifugation at $700 \mathrm{~g}$ for $5 \mathrm{~min}$ and stained by a modification of the amoniacal silver 168 carbonate method originally described by Fernández-Galiano (1994) and described in 169 detail by Budiño et al. (2011a).

170 The nuclear apparatus was visualized by fluorescence, after staining ciliates with 171 an aqueous solution of $0.4 \mu \mathrm{g} / \mathrm{ml}$ of 4'-6-diamidine-2-phenylindone (DAPI, Sigma172 Aldrich), in a Zeiss Axioplan microscope (Jena, Germany) equipped with a DAPI filter 173 set (BP 365/12; FT 395; LP 397) and in a Leica TCS SP2 laser scanning confocal 174 microscope (Leica Biosystems, Mannheim, Germany). 
175 Somatic and caudal cilia were measured in parasites fixed in $10 \%$ buffered 176 formaldehyde under phase contrast optics.

177 In some experiments of prey-induction transformation, the ciliates were stained 178 with the $\mathrm{pH}$ sensitive fluorescent acridine orange and observed in a fluorescence 179 microscope with an excitation BP 450/490 nm dichroic mirror filter and FT $510 \mathrm{~nm}$ LP 180 emission filter.

181 For histological study, tissues were fixed in $10 \%$ buffered formaldehyde solution, 182 dehydrated through an ethanol series, embe dded in Paraplast Plus (Sigma-Aldrich), 183 sectioned at 2-5 $\mu \mathrm{m}$ with a Leica RM 2135 rotary microtome (Leica Biosystems, 184 Germany), and stained with haematoxylin and eosin (H\&E) for examination by light 185 microscopy (Iglesias et al. 2001).

186

\section{Tomitogenesis and prey induction experiments}

188 For tomite transformation, cultures of $2 \times 10^{3}$ cells $/ \mathrm{ml}$ of $M$. avidus strain $\mathrm{Ma} / 2, P$. 189 dicentrarchi strain I1 and isolate Pe 5 in stationary phase were centrifuged at $700 \mathrm{~g}$ for 5 190 min, resuspended in non-nutrient synthetic seawater (NSS, 8 \%o salinity), and incubated 191 at $25^{\circ} \mathrm{C}$ (Gómez-Saladín \& Small, 1993a). In prey induction experiments, ciliates of $M$. avidus strain $\mathrm{Ma} / 2$ and $P$. dicentrachi strain $\mathrm{I} 1$ were incubated at a ratio of $1: 1$ in 24 -

193 well microplates for 5 days in NSS at $25^{\circ} \mathrm{C}$. The ciliates were observed daily under an 194 inverted optical microscope. When predation phenomena were observed, ciliates were 195 removed and centrifuged at $700 \mathrm{~g}$ for $5 \mathrm{~min}$. Some specimens $\left(10^{6}\right.$ ciliates $)$ were fixed 196 in buffered 10\% formaldehyde in phosphate buffer saline for later examination by phase 197 contrast microscopy, while other specimens $\left(10^{6}\right.$ ciliates $)$ were stained, using a 198 modification of the ammoniacal silver carbonate method, as described previously. 
200 PCR, cloning, and phylogenetic analyses

201 Cultured ciliates $\left(5 \times 10^{6}\right.$ cells $\left./ \mathrm{ml}\right)$ were harvested by centrifugation at $700 \mathrm{~g}$ for $5 \mathrm{~min}$. 202 The ciliates were washed twice with phosphate buffer saline (PBS) and total DNA was 203 purified with DNAeasy Blood and Tissue Kit (Qiagen) according to the manufacturer's 204 instructions. DNA was analyzed to estimate its quality, purity, and concentration by an $205 \mathrm{~A}_{260}$ measurement in a NanoDrop ND-1000 Spectrophotometer (NanoDrop 206 Technologies, USA.). The DNA was stored at $-20^{\circ} \mathrm{C}$ until use.

207 PCR amplification was performed as previously described (Leiro et al. 2000; 208 Budiño et al. 2011a), with minor modifications. A complete small-subunit ribosomal 209 RNA (SSUrRNA; 1,759 bp), a region of $388 \mathrm{bp}$ of the gene coding the $\beta$-tubulin, and a 210 region of $197 \mathrm{bp}$ of the gene coding the $\alpha$-tubulin were amplified. The primer sets were 211 designed and optimized by use of the Primer 3Plus program 212 (http://www.bioinformatics.nl/cgi-bin/primer3plus/primer3plus.cgi), with default 213 parameters. The PCR mixtures $(25 \mu \mathrm{l})$ contained PCR reaction buffer $(10 \mathrm{mM}$ Tris-HCl, $21450 \mathrm{mM} \mathrm{KCl}, 1.5 \mathrm{mM} \mathrm{MgCl} 2, \mathrm{pH} 9.0), 0.2 \mathrm{mM}$ of each deoxynucleoside triphosphate 215 (dNTPs, Roche), $0.4 \mu \mathrm{M}$ of each primer [forward 5'216 AATCTGGTTGATCCTGCCAGT-3' / reverse 5'-GATCCTTCCGCAGGTTCA-3' 217 (SSUrRNA); forward 5'-CCTACCACGGAGACTCTGATT-3' / reverse 5'218 CCATAATTCTGTCGGGGTATT-3' ( 3 -tubulin); forward 5'219 ATGCCCTCTGATAAAACCATC-3' / reverse 5'-GAGTCCGGTACAGTTGTCAG-3' 220 ( $\alpha$-tubulin)]; 0.5 units of high fidelity Taq polymerase (Nzyproof DNA polymerase; 221 Nzytech, Portugal) and $50 \mathrm{ng}$ of genomic DNA. The reactions were run in an automatic 222 thermocycler (iCycler, BioRad, USA) as follows: initial denaturing at $94{ }^{\circ} \mathrm{C}$ for $5 \mathrm{~min}$, 223 followed by 35 cycles at $94^{\circ} \mathrm{C}$ for $30 \mathrm{~s}$, annealing at 55, 57, and $64^{\circ} \mathrm{C}$ (for SSUrRNA, $224 \alpha$-tubulin and $\beta$-tubulin, respectively) for $45 \mathrm{~s}$, and $72{ }^{\circ} \mathrm{C}$ for $1 \mathrm{~min}$; and finally a $7 \mathrm{~min}$ 
225 extension phase at $72{ }^{\circ} \mathrm{C}$. The PCR products were analysed on a $4 \%$ agarose gel in tris 226 acetate ethylenediaminetetraacetic acid (TAE) buffer (40 mMTris-acetate, $\mathrm{pH}$ 8.0, 2 227 mM EDTA) containing Sybr Green at $1 \mathrm{x}$ concentration (Intron, Korea), to verify the 228 presence of bands of the correct size, and were photographed with a digital camera. The 229 PCR products were cloned in the pSpark ${ }^{\circledR}$ II DNA cloning vector kit (Canvax Biotech, 230 Spain) according to the manufacturer's instructions. After ligation of the PCR fragment, 231 the E. coli $\mathrm{DH}_{5 \alpha}$ cells were transformed and then selected on the basis of antibiotic 232 sensitivity and colour by culture on LB agar plates containing $100 \mu \mathrm{g} / \mathrm{ml}$ ampicillin, 233 with $50 \mu \mathrm{l}$ of a stock solution of $20 \mathrm{mg} / \mathrm{ml}$ of 5-bromo-4-chloro-3-indolyl- $\beta$-galactoside 234 (X-Gal) and $20 \mu \mathrm{l}$ of a $0.5 \mathrm{M}$ solution of isopropylthio- $\beta$-D-galactoside (IPTG) spread 235 on the surface. Ten E. coli white colonies per ligation sample were amplified in LB 236 medium and plasmid DNA was purified with the QiAaprep® Spin Miniprep kit (Qiagen, 237 Germany) according to the manufacturer's instructions. To confirm the presence of the 238 cloned fragment of the correct size, the fragment was amplified by PCR, with the 239 previously indicated primers and conditions. The PCR-amplified products were then 240 visualized by agarose gel electrophoresis and sequenced in complementary directions 241 (Sistemas Genómicos, Spain).

242 We used the BLAST interface and the blastn program optimized for very similar 243 sequences (megablast), available at http://blast.ncbi.nlm.nih.gov , to calculate the degree 244 of identity between the nucleotide sequences. Sequence alignment can be performed 245 directly online.

246 The complete nucleotide sequences of the SSUrRNA gene from isolates Pe5 and 247 Pe7 from fine flounder, strain I1 of $P$. dicentrarchi isolated from turbot, and strain $\mathrm{Ma} / 2$ 248 of $M$. avidus ( $\mathrm{ATCC}^{\circledR} 50180^{\mathrm{TM}}$ ) were compared with equivalent sequences from strains 249 YK2 and YS2 of M. avidus isolated from olive flounder (accession numbers EU831208 
250 and EU831200; Jung et al., 2011) and with other species of the order Philasterida

251 (Table 1). The sequences were aligned with Clustal Omega (McWilliam et al., 2013)

252 and phylogenetic trees were inferred by the neighbour-joining (NJ) method (Saitou \& 253 Nei, 1987). This method was applied to the Kimura two-parameter correction model 254 (Kimura, 1980) by bootstrapping with 1,000 replicates (Felsenstein, 1985) from 255 multiple alignments and consensus of the study sequences with Clustal Omega software 256 (Sievers et al. 2011). The tree is drawn to scale, with branch lengths in the same units as 257 those of the evolutionary distances used to infer the phylogenetic tree. All positions 258 containing gaps and missing data were eliminated and evolutionary analyses were 259 conducted in MEGA7 (Kumar et al. 2016)

260

261 Production of recombinant alpha-tubulin (r- $\alpha$ Tub) of $P$. dicentrarchi in 262 yeast cells

263 RNA isolated from Philasterides dicentrarchi was purified with a NucleoSpin RNA kit 264 (Macherey-Nagel, Düren, Germany) according to the manufacturer's instructions. After 265 purification of the RNA, the quality, purity, and concentration were measured in a 266 NanoDrop ND-1000 Spectrophotometer (NanoDrop Technologies, USA). The reaction 267 mixture used for cDNA synthesis $(25 \mu \mathrm{l} /$ reaction mixture) contained $1.25 \mu \mathrm{M}$ random 268 hexamer primers (Promega), $250 \mu \mathrm{M}$ of each deoxynucleoside triphosphate (dNTP), 10 $269 \mathrm{mM}$ dithiothreitol (DTT), $20 \mathrm{U}$ of RNase inhibitor, $2.5 \mathrm{mM} \mathrm{MgCl}_{2}, 200 \mathrm{U}$ of MMLV 270 (Moloney murine leukemia virus reverse transcriptase; Promega) in $30 \mathrm{mM}$ Tris and 20 $271 \mathrm{mM} \mathrm{KCl}(\mathrm{pH} 8.3)$, and $2 \mu \mathrm{g}$ of sample RNA. The PCR was carried out with gene272 specific primers designed from a partial sequence of the $\alpha$-tubulin of $P$. dicentrarchi 273 (forward/reverse primer pair 5'274 AAAGAAGAAGGGGTACCTTTGGATAAAAGAatgccetctgataaaaccatc-3' / 5'- 
TGGGACGCTCGACGGATCAGCGGCCGCTTAGTGGTGGTGGTGGTGGTGgagtc

276 cggtacagttgtcag-3'). These primers were designed and optimized, using the

277 Saccharomyces Genome Database (http://www.yeastgenome.org/). A hybridization

278 region with the yeast YEpFLAG-1 (Eastman Kodak Company) plasmid and a poly His

279 region (lower case letters correspond with the gene annealing zone) were included. The

280 PCR reaction was initially developed at $95^{\circ} \mathrm{C}$ for $5 \mathrm{~min}$, and then for 30 cycles of $94{ }^{\circ} \mathrm{C}$

281 for $1 \mathrm{~min}, 53{ }^{\circ} \mathrm{C}$ for $1.5 \mathrm{~min}$ and $72{ }^{\circ} \mathrm{C}$ for $2 \mathrm{~min}$. At the end of the 30 cycles, a 7 -min

282 extension phase was carried out at $72{ }^{\circ} \mathrm{C}$. The PCR products were purified by using the

283 Gene Jet PCR Purification Kit (Fermentas, Life Sciences) according to the 284 manufacturer's instructions.

285 Purified PCR products were cloned in YEpFLAG-1 (Eastman Kodak Company) 286 yeast expression vector, a plasmid carrying a TRP1 gene that completes the auxotrophy 287 for the tryptophan for the host yeast (López-López et al. 2010).

288 Linearized plasmid YEpFLAG-1 was digested with EcoRI and SalI (Takara) and 289 used to transform Saccharomyces cerevisiae cells (strain BJ 3505) by the lithium 290 acetate procedure (Ito et al. 1983). The procedure involves co-transformation of yeast 291 cells with the linearized empty plasmid and the PCR-generated DNA fragment, so that a 292 recombination process occurs within the cell to yield a plasmid bearing the desired 293 insert. Positive colonies were selected on complete medium containing glucose (20 g/l), 294 but without tryptophan (CM-Trp), Yeast Nitrogen Base medium without amino acids 295 (Sigma-Aldrich), except for the amino acids arginine, methionine and threonine at 10 $296 \mathrm{mg} / \mathrm{l}$; adenine, histidine, leucine, lysine, and tyrosine at $40 \mathrm{mg} / \mathrm{l}$; and isoleucine and 297 phenylalanine at $60 \mathrm{mg} / \mathrm{l}$. 
Plasmid DNA was then extracted with Easy Yeast Plasmid Isolation Kit

299 (Clonetech) according to the manufacturer's instructions. The purified and cloned DNA

300 fragment was subjected to sequencing analysis (Sistemas Genómicos, Spain).

301

302 Inoculation and polyclonal mouse antisera

303 CD-1 mice were inoculated i.p. with $200 \mu \mathrm{l}$ of a 1:1 emulsion composed of $100 \mu \mathrm{l}$ of a 304 solution of $100 \mu \mathrm{g}$ of $\mathrm{r}-\alpha \mathrm{Tub}$ of the strain I1 of $P$. dicentrarchi in PBS and $100 \mu \mathrm{l}$ of 305 Freund complete adjuvant (Sigma-Aldrich). The same dose of r- $\alpha$ Tub protein was 306 prepared in Freund's incomplete adjuvant and injected i.p. in mice 15 and 30 days after

307 the first immunization. The mice were bled via retrobulbar venous plexus seven days 308 after the second inoculation. The blood was left to coagulate overnight at $4{ }^{\circ} \mathrm{C}$ before 309 the serum was separated by centrifugation (2000 $g$ for $10 \mathrm{~min})$, mixed 1:1 with glycerol, 310 and stored at $-20^{\circ} \mathrm{C}$ until use (Piazzon et al. 2011).

\section{Immunoassays}

313 For Western-blot assay, integral ciliate membrane-associate proteins (CMP) of 314 scuticociliates were prepared as previously described (Iglesias et al. 2003b), with minor 315 modifications (Mallo et al. 2013). Briefly, scuticociliate trophozoites were deciliated by 316 the method described by Dickerson et al. (1989). The integral proteins were extracted 317 by phase separation in Triton X-114 solution according to the method described by 318 Bordier (1981). The proteins were precipited with cold acetone, and the precipitate was 319 dried in a Speed Vac concentrator and stored at $-80^{\circ} \mathrm{C}$ in $10 \mathrm{mM}$ Tris-HCl, pH 7.5. 320 Samples from CMP were separated under non-reducing conditions on linear SDS321 PAGE $12.5 \%$ gels (Piazzon et al. 2008). On completion of the electrophoresis, the gels 322 were stained with Thermo Scientific GelCode Blue Safe Protein Stain (Thermo Fisher, 
323 USA) for qualitative determination of the protein bands. At the same time, a gel was

324 immunoblotted at $15 \mathrm{~V}$ for 35 min to Immobilon-P transfer membranes $(0.45 \mu \mathrm{m}$;

325 Millipore, USA) in a trans-blot SD transfer cell (Bio-Rad, USA) with transference 326 buffer (48 mM Tris, $29 \mathrm{mM}$ glycine, $0.037 \%$ SDS and $20 \%$ methanol, $\mathrm{pH} 9.2$ ). The 327 membrane was washed with Tris buffer saline (TBS; $50 \mathrm{mM}$ Tris, $0.15 \mathrm{M} \mathrm{NaCl}$, $\mathrm{pH}$ 328 7.4) and immediately stained with Ponceau S to verify transfer. After destaining the 329 membrane with bidistilled water, a blocking solution consisting of TBS containing $0.2 \%$ 330 Tween 20 and 3\% BSA was added. The membrane was incubated for $1.5 \mathrm{~h}$ at room 331 temperature and then washed in TBS and incubated overnight with the mouse 332 polyclonal antisera anti-r- $\alpha$ Tub (1:500 dilution) at $4{ }^{\circ} \mathrm{C}$. The membrane was washed 333 again with TBS and incubated with rabbit anti-mouse IgG (Dakopatts; dilution 1:6000) 334 for $1 \mathrm{~h}$ at room temperature. The membrane was then washed five times for $5 \mathrm{~min}$ with 335 TBS and incubated for 1 min with enhanced luminol-based chemiluminiscent substrate 336 (Pierce ECL Western Blotting Substrate, Thermo Scientific, USA), before finally being 337 visualized and photographed with a FlourChem ${ }^{\circledR}$ FC2 imaging system (Alpha Innotech, 338 USA).

339 The immunofluorescence assay was performed according to the previously 340 described protocol (Mallo et al. 2015, 2016). Briefly, 5 x $10^{6}$ ciliates were centrifuged 341 at $750 \mathrm{~g}$ for $5 \mathrm{~min}$, washed twice with Dulbecco's phosphate buffered saline (DPBS, 342 Sigma Aldrich) and fixed for $5 \mathrm{~min}$ in a solution of $4 \%$ formaldehyde in DPBS. The 343 ciliates were then washed twice with DPBS, resuspended in a solution containing $0.1 \%$ 344 Triton X-100 (PBT) for $3 \mathrm{~min}$ and then washed twice with DPBS. They were then 345 incubated with $1 \%$ bovine serum albumin (BSA) for 30 min. After this blocking step, 346 the ciliates were incubated at $4{ }^{\circ} \mathrm{C}$ overnight with a solution containing a 1:100 dilution 347 of anti-r- $\alpha$ Tub. The ciliates were then washed three times with DPBS and incubated, for 
$3481 \mathrm{~h}$ at room temperature, with a 1:100 dilution of FITC conjugated rabbit/goat anti349 mouse IgG-FITC antibody (Sigma) or with the same dilution of Alexa Fluor 546 350 conjugated goat anti-mouse Ig (Molecular Probes). After three washing steps in DPBS, 351 the samples were double-stained with $0.8 \mathrm{mg} / \mathrm{ml}$ 4', 6-diamidine-2-phenylindole (DAPI; 352 Sigma-Aldrich) in DPBS for $15 \mathrm{~min}$ at room temperature (Paramá et al. 2007). After 353 another three washing steps in DPBS, the samples were mounted in PBS-glycerol $(1: 1)$ 354 and visualized by fluorescence microscopy (Zeiss Axioplan, Germany) and/or confocal 355 microscopy (Leica TCS-SP2, LEICA Microsystems Heidelberg GmbH, Mannheim, 356 Germany).

357 The enzyme-linked immunosorbent assay (ELISA) was performed as previously 358 described (Iglesias et al. 2003b), with minor modifications. One $\mu$ g of CMP in $100 \mu \mathrm{l}$ of 359 carbonate-bicarbonate buffer ( $\mathrm{pH}$ 9.6) was added to 96-well ELISA plates (high binding, 360 Greiner Bio-One, Germany) and incubated overnight at $4{ }^{\circ} \mathrm{C}$. The wells were then 361 washed three times with TBS and blocked for $1 \mathrm{~h}$ with TBS containing $0.2 \%$ Tween 20 362 (TBS- $\left.\mathrm{T}_{1}\right)$ and $5 \%$ non-fat dry milk. The plates were incubated for $30 \mathrm{~min}$ at room 363 temperature in a microplate shaker for ELISA (Stuart, UK) at $750 \mathrm{rpm}$ with a 1:100 364 dilution (in TBS- $T_{1}$ containing $1 \%$ non-fat dry milk) of anti-r- $\alpha$ Tub, and washed five 365 times with TBS containing $0.05 \%$ Tween 20 . Bound mouse antibodies were detected 366 with a peroxidase-conjugated anti-mouse Ig polyclonal rabit serum (DAKO) diluted 367 1:1000 in TBS- $\mathrm{T}_{1}$, and incubated for $30 \mathrm{~min}$ with shaking. The plates were washed five 368 times in TBS, and $100 \mu \mathrm{l}$ of $o$-phenylenediamine dihydrochloride (OPD, Sigma369 Aldrich) and $0.003 \% \mathrm{H}_{2} \mathrm{O}_{2}$ were added to each well. After incubation of the plates for $37020 \mathrm{~min}$ at room temperature in darkness, the enzymatic reaction was stopped by adding $37125 \mu \mathrm{l}$ of $\mathrm{H}_{2} \mathrm{SO}_{4}$ at $3 \mathrm{~N}$. Finally, the absorbance was read at $492 \mathrm{~nm}$ in a 372 spectrophotometer microplate reader (Bio-Tek Instruments, USA). 


\section{Statistical analysis}

374 Results are expressed as means \pm standard error of means. Data were tested by one-way 375 analysis of variance (ANOVA) followed by a Tukey-Kramer test for multiple 376 comparisons. Differences were considered significant at $P<0.05$.

378 RESULTS

Description of an outbreak of scuticociliatosis in the fine flounder 381 Paralichthys adspersus

The outbreak of scuticociliatosis coincided with water temperatures higher than

$38321-22{ }^{\circ} \mathrm{C}$. The main external symptoms of the affected fish were alterations in skin 384 pigmentation and emaciation (Fig. 1A), gills congested with mucus and abundant 385 aneurysms (Fig. 1B, D), exophthalmia, and abdominal distension with ascitic fluid, 386 from which ciliates were isolated (Fig. 1C). At the histopathological level, the main 387 pathology was associated with systemic necrosis affecting several organs including the 388 heart, with severe necrosis of myocardium (Fig. 1D).

389

Description of the Peruvian population (isolates Pe5 and Pe7) infecting the fine flounder P. adspersus (Fig. 2A-I; Table 2)

The main characteristics of the cilates isolated from the fine flounder are as

393 follows: cells elongated and spindle-shaped, with a pointed anterior and rounded 394 posterior end, a contractile vacuole, and a prominent caudal cilium (Fig. 2B, E, G, I, 395 3C). The buccal apparatus always contained two paroral membranes (PM1 and PM2) 396 and three oral membranoids or polykinetids (M1, M2, and M3) (Fig. 2A, D, F, H), 
397 showing identical morphology to that of Philasterides dicentrarchi (Fig. 2C). PM1 398 extends from the start of M1 to the start of M3, while PM2 extends from the middle of 399 M3 to the end of the oral cavity (Fig. 2A, C, D, F, H). M1 is elliptical, M2 is trapezoidal, 400 and M3 is smaller that M1 and M2, and irregularly triangular (Fig. 2A, C, D, F, H). The 401 somatic ciliature of the Pe5 and Pe7 isolates consists of 10-13 kineties, and the pore of 402 the subterminal contractile vacuole is at the posterior end of the second kinety (Fig. 2B, 403 E, G, I).

404 The morphometric data of the Pe5 and Pe7 isolates are summarized in Table 2, 405 in which they are compared with the morphometric data available for $P$. dicentrarchi 406 isolated from turbot (strain I1; present study) and from seabass (Dragesco et al. 1995), 407 and for M. avidus isolated from seahorses (Thompson \& Moevus 1964) as well as with 408 own data from of strain $\mathrm{Ma} / 2$ of Miamiensis avidus Thompson \& Moewus $409 \quad\left(\mathrm{ATCC}^{\circledR} 50180^{\mathrm{TM}}\right)$ stained with ammoniacal silver carbonate and $P$. dicentrachi strain 410 I1. The ranges of the morphological data on isolates Pe5 and Pe7 generally overlap 411 those of $P$. dicentrarchi strain I1, of the original species description of M. avidus, and of 412 M. avidus held by the ATCC. At the morphological level, isolates Pe5 and Pe7 and P. 413 dicentrarchi strain I1 differ several morphological features from M. avidus (ATCC), 414 such as the lack of a peak at the frontal part of trophozoites (Fig. 2M), the lack of a 415 continuous paroral membrane (PM; Fig. 2J, K, L), and the morphology of the tomites, 416 which are elongated and fusiforms in the latter species (Fig. 2N, O). In contrast to $M$. 417 avidus (ATCC), the $P$. adspersus isolates Pe5 and Pe7 as well as $P$. dicentrarchi have a 418 prominent caudal cilium that is longer than the somatic cilia (Fig. 3C). In $P$. 419 dicentrarchi, the mean length of the caudal cilium was $11.4 \pm 2.0 \mu \mathrm{m}(15 \mu \mathrm{m})$ and of 420 the somatic cilia was $5.6 \pm 1.0 \mu \mathrm{m}(5-8 \mu \mathrm{m})$. In $M$. avidus strain $\mathrm{Ma} / 2$, the mean 
421 length of the caudal cilium was $9.3 \pm 2.1 \mu \mathrm{m}(7-11 \mu \mathrm{m})$ and that of the somatic cilia,

$422 \quad 6.6 \pm 1.1 \mu \mathrm{m}(5-9 \mu \mathrm{m}, \mathrm{n}=20)$.

423 The nuclear apparatus of isolates Pe5 and Pe7 and strain I1 of P. dicentrarchi

424 consists of a spherical macronucleus located mainly in the middle or anterior third of

425 the trophozoite, slightly lateralized, and between 4-8 $\mu \mathrm{m}$ in diameter (Table 2; Fig. 3A-

426 C). The micronucleus, $1-2 \mu \mathrm{m}$ in diameter, has a variable posterior position in isolates

427 Pe5 and Pe7 and strain I1 of $P$. dicentrarchi (Fig. 3A-C), (Table 2). In M. avidus strain

$428 \mathrm{Ma} / 2$, the macronucleus is irregularly spherical and usually located in the anterior cell

429 half. The micronucleus anterior or laterally of the macronucleus (Fig. 3D).

430

\section{Tomitogenesis and predatory transformation}

432 Most polymorphic hymenostomes and scuticociliates have morphologically distinct

433 feeding stages including a bacteriovorus microstome, a predatory macrostome, and

434 sometimes a non-feeding, fast swimming tomite (Fig. 4). In culture media containing 435 nutrients, M. avidus strain Ma/2 produced macrostome and microstome forms (Fig. 4A),

436 wihile all strains of $P$. dicentrarchi only produced microstome forms (Fig. 4C). Under 437 conditions of nutrient deprivation, M. avidus $\mathrm{Ma} / 2$ produced some macrostome and 438 microstome forms and numerous tomites (Fig. 4B) P. dicentrarchi appeared almost 439 exclusively as tomites (Fig. 4D). In M. avidus strain Ma/2, the macrostomes measured $44050.1 \pm 9.4 \times 35.4 \pm 5.2 \mu \mathrm{m}(37-65 \times 28-44 \mu \mathrm{m}, \mathrm{n}=10)$ and the tomites $22.4 \pm 4.5 \times$

$441 \quad 10.5 \pm 2.7 \mu \mathrm{m}(23-28 \times 7-13 \mu \mathrm{m}, \mathrm{n}=10)$. In $P$. dicentrarchi, the length/width of the 442 tomite was $20.6 \pm 2.7 \times 13.1 \pm 2.1(17-24 \times 11-16 \mu \mathrm{m}, \mathrm{n}=10)$.

443 To verify which of the species considered in this study developed predatory 444 macrostome phases, we co-cultured trophozoites of $M$. avidus strain $\mathrm{Ma} / 2$ with 445 trophozoites of $P$. dicentrarchi strain I1, and trophozoites of strain I1 with isolate Pe7, 
446 in media without nutrients. On the second day, the co-cultures of M. avidus strain Ma/2

447 and $P$. dicentrarchi strain I1 showed predatory macrostome forms (Fig. 5A-D); however, 448 this phenomenon was not detected in the co-cultures of Pe7 and I1 isolates. We found 449 that $M$. avidus is a predator of $P$. dicentrarchi strain I1. To reach this conclusion, we 450 obtained genomic DNA from $M$. avidus and $P$. dicentrarchi from 5 day co-cultures at 451 day 5 and amplified it by PCR (Fig. 5E), using the primers designed for P. dicentrarchi 452 DNA genes and showing low ( $\alpha$-tubulin), very low ( $\beta$-tubulin) and high (SSUrRNA) 453 nucleotide identity with the same genes in M. avidus (Fig. 5F). In all cases, we observed 454 amplification of the SSUrRNA gene, slight amplification of the $\alpha$-tubulin gene, and 455 non-amplification of the $\beta$-tubulin gene in DNA samples obtained from cultures of the 456 strain $\mathrm{Ma} / 2$ of $M$. avidus and in DNA samples from co-cultures of $M$. avidus and $P$. 457 dicentrarchi (Fig. 5E, a-c). We then cloned and sequenced the amplified fragments of $458 \alpha$-tubulin and SSUrRNA genes from co-cultures of $M$. avidus strain $\mathrm{Ma} / 2$ and $P$. 459 dicentrarchi strain I1, observing that the nucleotide sequence obtained coincided with 460 those of M. avidus Ma/2 (Fig. 5E, a, c).

461

462 Infectivity of $M$. avidus strain $M a / 2$

463 The M. avidus strain $\mathrm{ATCC}^{\odot} 50180^{\mathrm{TM}}$ was originally isolated from infected 464 seahorses; however, we did not know whether the species could infect flatfish. In this 465 experiment, we inoculated turbot by intraperitoneal injection with $M$. avidus, using the 466 same dose as used for $P$. dicentrarchi strain I1 ( $10^{5}$ ciliates/fish). We observed that $M$. 467 avidus strain $\mathrm{Ma} / 2$ is highly pathogenic to turbot, generating abdominal distension with 468 a significant presence of ascitic liquid, from which it was possible to isolate ciliates (Fig. 469 6A), and causing $100 \%$ mortality in infected fish on day 5 (Fig. 6B).

470 
471 Molecular analysis of the scuticociliates

472 The full length SSUrRNA sequences of Pe5, Pe7, and P. dicentrarchi strain I1

473 (Accession $\mathrm{n}^{\mathrm{o}}$ JX914665.1; Leiro et al. 2012, unpublished) showed 100\% identity with 474 each other and 96\% identity with $M$. avidus strain Ma/2 (Accession KX357144; Table $4753 \mathrm{~A})$. We compared the above- mentioned $18 \mathrm{~S}$ sequences with those obtained from the 476 GenBank for M. avidus isolate YK2 (Accession nº EU831208.1; Jung et al. 2011), M. 477 avidus isolate YS2 (Accession EU831200.1; Jung et al. 2011), M. avidus isolate 478 FXP2009050602 (Accession JN885091.1; Gao et al. 2012), and strain GF2008082801 479 of Philasterides armatalis Song, 2000 (Accession FJ848877; Gao et al. 2009). 480 Miamiensis avidus strains YK2 and YS2 showed 99\% identity with $P$. dicentrachi strain 481 I1, Pe5 and Pe7 isolates, 96\% identity with M. avidus strain Ma/2 or M. avidus isolate 482 FXP2009050602, and 95\% identity with P. armatalis (Table 3A). The phylogenetic tree 483 constructed, using the Neighbour-joining (NJ) model grouped Pe5, Pe7, P. dicentrachi 484 strain I1 in the same node and closely related to strains YK2, YS2 (Fig. 7A), while $M$. 485 avidus strain Ma/2 from ATCC and the M. avidus isolate FXP2009050602 grouped in a 486 different node together with the Anophryoides haemophila (Fig. 7A). Analysis of the 487 similarity between the nucleotide sequences corresponding to fragments of the $\alpha$ - (strain $488 \mathrm{I}$, accession $\mathrm{KX} 357145$; strain $\mathrm{Ma} / 2$, accession $\mathrm{KX} 357143$ ) and $\beta$-tubulin genes (strain 489 I1, accession CQ342956.1; strain Ma/2 accession KX357147) revealed 99-100\% 490 identity between isolates Pe5, Pe7 and strain I1, but only $89 \%$ identity for $\alpha$-tubulin and $49185 \%$ identity for $\beta$-tubulin with $M$. avidus strain $\mathrm{Ma} / 2$ or $81-83 \%$ of identity for $\alpha$ 492 tubulin with M. avidus isolate FXP2009050602 (Table 3B). Phylogenetic trees 493 generated after alignments of the nucleotide sequences of the $\alpha$ - and $\beta$-tubulin genes for 494 the Pe5 and Pe7 isolates and I1 and the Ma/2 strains, using the model NJ, grouped Pe5, 
495 Pe7 and I1 in one node and the M. avidus Ma/2 strain or isolate FXP2009050602 in a 496 different node (Fig 7B, C).

497

498

Antigenic relationships between ciliates isolated from flatfish and $M$. 499 avidus strain $\mathrm{Ma} / 2$

500 We generated a recombinant protein from a partial sequence of the gene 501 encoding this protein (r- $\alpha \mathrm{Tub})$ in $P$. dicentrarchi strain $\mathrm{I} 1$, to compare the antigenic 502 homology between the $\alpha$-tubulin of the scuticociliates Pe5, Pe7, I1, and M. avidus strain $503 \mathrm{Ma} / 2\left(\mathrm{ATCC}^{\circledR} 50180^{\mathrm{TM}}\right.$ ) (Fig. 8A). The antibodies generated in mice following 504 inoculation with the recombinant protein were used to perform three immunoassays to 505 determine the level of cross-reactivity with this protein in the isolates/strains studied.

506 We first performed an immunofluorescence test to verify the level of recognition 507 by anti-r- $\alpha$ Tub antibodies on the Pe 5 andPe 7 isolates and the $\mathrm{I} 1$ and Ma/2 strains. We 508 found that the antibodies recognised the $\alpha$-tubulins in all four samples and, at the 509 concentrations used, we did not find any qualitative differences in the staining intensity 510 (Fig. 8B-E).

511 Quantitative immunoassays as ELISA revealed that the levels of recognition of 512 native ciliary proteins containing $\alpha$-tubulin in the Pe7 isolate were similar to those 513 obtained with strain I1; however, these levels were significantly lower when antigens of 514 strain Ma/2 of M. avidus were used (Fig. 8F).

515 Western blot carried out under reducing conditions revealed two bands of about 51650 and $60 \mathrm{kD}$ in ciliary isolated fractions of isolate Pe7 and strain I1. However, no 517 bands were detected when antigens from M. avidus strain Ma/2 were included (Fig. 8G). 518 519 


\section{DISCUSSION}

521 Here we describe a scuticociliate infection in the fine flounder Paralichthys 522 adspersus, cultivated in Peru. The infection occurred on a fish farm with a water

523 recirculation system, which appears to increase the risk of scuticociliatosis (Budiño et al.

524 2011b), and at high temperatures, another risk factor for development of this disease

525 (Iglesias et al. 2001; Moustafa et al. 2010).

526 We did not conduct a complete histopathological study of the scuticociliatosis in

527 P. adspersus and only observed that the clinical signs and pathology generated by the

528 ciliates are very similar to those produced in Scophthalmus maximus (Linnaeus, 1758)

529 and the olive flounder Paralichthys olivaceus (Temminck \& Schlegel, 1846) (Iglesias et

530 al. 2001; Jung et al. 2007; Moustafa et al. 2010; Harikrishnan et al. 2012). Our research

531 primarily focused on the identification of the causative agent of the disease in $P$.

532 adspersus. In all samples, the buccal apparatus of the ciliate isolates Pe5 and Pe7 from

533 P. adspersus contained two paroral membranes (PM1 and PM2) and three oral

534 polykinetids (M1, M2 and M3), with identical arrangement and morphology to that

535 described for Philasterides dicentrarchi (Dragesco et al. 1995; Iglesias et al. 2001;

536 Budiño et al. 2011a). According to the redescription of the genus Philasterides Kahl,

5371926 by Grolière (1980), the type species Philasterides armata has a split paroral

538 membrane and three equidistant adoral poykinetids (M1, M2, and M3). However, of the

539 two paroral membranes is debated as it is uncertain whther it respresent a fixed

540 character that includes this species in the genus Philasterides or may show an

541 intraspecific variability and is thus not suitable for species identification (Jung et al.

542 2007).

543 Song \& Wilbert (2000) redescribed M. avidus, using the dimorphic paroral 544 membrane with its monokinetidal anterior and its dikinetidal posterior part slightly 
545 separated as its main morphological characteristic, thereby synonymizing $M$. avidus

546 and $P$. dicentrarchi. However, the morphological data of the present study clearly 547 shows that both isolates obtained from P. adspersus (isolates Pe5 and Pe7) have two 548 clearly separated paroral membranes, while $M$. avidus strain $\mathrm{Ma} / 2$ has invariably a 549 single continuous paroral membrane. The original description of M. avidus mentions 550 that a narrow gap "sometimes" appears between the anterior and posterior paroral 551 portions; however, this does not seem to be common in this species, as indicated by the 552 fact that the authors described the paroral as a unit, measuring its length from its 553 anterior to its posterior end until the anterior end (Thompson \& Moewus, 1964). In 554 contrast to M. avidus, the presence of a bipartite paroral membrane (PM1 and PM2), 555 seems thus to be a constant morphological feature in P. dicentrarchi (Dragesco et al. 556 1995; Iglesias et al. 2001; Budiño et al. 2011a).

557 Jung et al. (2007) found that a scuticociliate isolate (YS1 strain) from olive 558 flounder, identified as M. avidus, has one or two paroral membranes and two or three 559 oral polykinetids, the authors concluded that the morphology of buccal structures 560 "cannot be used as a consistent key for identification of the species". However 561 variability reported by Jung et al. (2007), might the result of a stomatogenic sequence in 562 the organelles membranoidogenesis, which is very common in several species of 563 scuticociliates (Miao et al. 2010). Some studies clearly show that M. avidus has a 564 continuous paroral membrane; only in the first phases of stomatogenesis (during the 565 transformation of microstomes into to macrostomes), the paroral membrane is divided, 566 with a small segment at the posterior end (Gómez-Saladín \& Small, 1993a).

567 The morphology of oral polykinetids M1, M2, and M3 in isolates Pe5 and Pe7 568 and Philasterides dicentrarchi strain I1 is very similar to that observed in M. avidus; but 569 differs from the oral polykinetids of congeners. the M1 of isolates Pe5 and Pe7 and 
570 strain I1 of $P$. dicentrarchi is elongated like the M1 of M. avidus (Thompson \&

571 Moewus, 1964), while the M1 of $P$. armata and $P$. armatalis is usually triangular

572 (Grolière 1980; Song et al. 2000); the M3 in P. dicentrarchi strain I1 and in the isolates

$573 \mathrm{Pe} 5$ and Pe7 is irregularly triangular and similar to M. avidus (Thompson \& Moewus,

574 1964), but different from the rectangular M3 of $P$. armata (Grolière, 1980).

575 During early and late phases of equal fission, most ciliates share certain features,

576 such as common position of macronucleus and micronucleus, synchronization of

577 macronuclear amitosis and fission furrow, and a specific and well defined dividing size

578 (Long \& Zufall, 2010). The position of the micronucleus relative to the macronucleus is

579 not specified in the original descriptions of $P$. dicentrarchi and $M$. avidus, which only

580 states that the micronucleus is closely associated with the macronucleus but completely

581 separate from it in P. dicentrarchi (Dragesco et al. 1995; Paramá et al. 2006); however,

582 some later descriptions proposed the anterior position of the micronucleus relative to the

583 macronucleus as a specific characteristic of M. avidus (Hu et al. 2009). In this study, we

584 clearly demonstrate that the position of the micronucleus relative to the macronucleus in

$585 \mathrm{Pe} 5, \mathrm{Pe} 7$ isolates and in strain $\mathrm{I} 1$ of $P$. dicentarchi is very variable.

586 The formation of tomites, which is a general characteristic of scuticociliates,

587 occurs in response to starvation without cyst production, or in response to drugs

588 (Fenchel, 1987; Gómez-Saladín \& Small, 1993b, Morais et al. 2009). Miamiensis

589 avidus is a known tomite-producing scuticociliate (Thompson \& Moewus, 1964;

590 Gómez-Saladin \& Small, 1993a; b). The life cycles of scuticociliates provide further

591 taxonomically significant features. While $M$. avidus undergoes microstome to

592 macrostome transformation following a considerable change in cell size and the buccal

593 structures (Small, 1967; Gómez-Saladin \& Small, 1993a), such a transformation was

594 not observed in P. dicentrarchi (Dragesco et al. 1995). In the present study, we 
595 performed tomitogenesis and prey-induced transformation experiments with $M$. avidus 596 strain $\mathrm{Ma} / 2, P$. dicentrarchi strain I1 isolated from P. adspersus, and isolate Pe7 in a 597 nutrient-depleted medium. We observed induction of the macrostome forms only in $M$. 598 avidus strain $\mathrm{Ma} / 2$, and in co-cultures of this strain $\mathrm{Ma} / 2$ with the $P$. dicentrarchi strain 599 I1; however, this phenomenon does not occur when I1 trophozoites were incubated with 600 trophozoites of isolates (Pe7) of fine flounder, and neither macrostome forms nor any 601 sign of predation/cannibalism could be detected.

602 The scuticociliate isolates Pe5 and Pe7 from the fine flounder P. adspersus and 603 P. dicentrarchi strain I1 are obviously virulent in their hosts; however, the infective 604 capacity of the $M$. avidus strain $\mathrm{Ma} / 2$, which has been maintained in culture for a long 605 time (more than 40 years) in the ATCC collection (Soldo \& Merlin, 1972), in unknown 606 In the present study, we demonstrated the high virulence of the strain Ma/2, causing a 607 mortality of $100 \%$ in turbot after experimental infection.

608 Identification of scuticociliates only on the basis of morphological features may 609 lead to misidentification (Whang et al. 2013). To solve this problem, molecular 610 techniques, mainly on the analysis of the small subunit rRNA gene (SSUrRNA) are 611 used. Besides barcoding for identification, they also enable clarification of the 612 phylogenetic relationships and the taxonomy of scuticociliates (Gao et al. 2012). The 613 phylogenetic analysis reveal a cluster of $P$. dicentrarchi strains I1 and isolates Pe7 and 614 Pe5 as sister group of strains YK2 and YS2, which from olive flounder, that had been 615 identified as M. avidus (syn. P. dicentrarchi) (Song \& Wilbert, 2000; Jung et al. 2007) 616 and whose SSUrRNA gene sequence data have been described in previous studies by 617 Jung et al. (2005) and Song et al. (2009a; b). Miamiensis avidus strain Ma/2, which is 618 considered to represent the "real" M. avidus and the isolate FXP2009050602, a strain 619 that is very morphologically similar to M. avidus described by Song \& Wilbert (2000), 
620 but differs in some morphological characteristics, and shows great differences at the

621 molecular level with the strains from Korea (Jung et al. 2011; Gao et al. 2012), together

622 and both are related to Anoprhyoides haemophila, a species that has already been

623 included with M. avidus in the family Parauronematidae on the basis of SSUrRNA

624 topologies (Gao et al. 2012). These results therefore indicate that the Peruvian isolates

625 from $P$. adspersus are similar to $P$. dicentrarchi and closely related to strains YK2 and

626 YS2; however, they are phylogenetically most distant from strain Ma/2 and isolate

627 FXP2009050602 of $M$. avidus. To corroborate this, we compared the $\alpha / \beta$ tubulin gene

628 sequences in $P$. dicentrarchi and $M$. avidus strain Ma/2 held in the ATCC and isolate

629 FXP2009050602 of $M$. avidus provide valuable information about the taxonomic

630 position of the species analyzed (Stoeck et al. 2000; Schmidt et al. 2006; Barth et al.

631 2006; Budiño et al. 2011a). $\alpha$ - and $\beta$-tubulin genes are suitable phylogenetic markers

632 discriminating strains and investigat the intraspecific genetic variability in $P$.

633 dicentrarchi (Budiño et al. 2011a). The nucleotide sequences identity of $99 \%$ and 100\%,

634 respectively in the $\alpha$ - and $\beta$-tubulin genes, indicate a conspecificity. The differences

635 between the $P$. dicentrarchi strains and $M$. avidus strain Ma/2 were also confirmed at

636 serological level. Although serological tests are widely used for identification in other

637 protozoa (de Waal, 2012), they are not usually used to diagnose ciliate infections in fish.

638 Nonetheless, they have proved very useful for characterizing and distinguishing antigens

639 from $P$. dicentrarchi and $M$. avidus, expressed during infection in turbot and in olive

640 flounder, and thus to differentiate strains (Piazzon et al. 2008; Song et al. 2009b;

641 Budiño et al. 2012). These findings confirm the above-mentioned genetic findings on

642 comparing the nucleotide sequences of the gene encoding this protein.

643 Final conclusion. The morphological analysis, tomitogenesis and prey-induced 644 transformation, comparisons of SSUrRNA and $\alpha / \beta$ tubulin gene sequences, and 
645 serological analysis all clearly indicate that isolates Pe5 and Pe7 and P. dicentrarchi

646 strain I1 are not conspecific with $M$. avidus strain Ma/2 (ATCC). We also found that $P$. 647 dicentrarchi displayed low identity in SSUrRNA sequences with P. armatalis. The low 648 identity (based on the nucleotide sequences of this gene) between $P$. dicentrarchi and $P$. 649 armatalis was also described by Gao et al. (2012).

650 Until the nucleotide sequences of the $18 \mathrm{~S}$ gene of the type species $P$. armatalis 651 becomes available, we cannot definitely confirm that this species belongs to the genus 652 Philasterides, or whether it should be transferred to another genus, or even propose its 653 inclusion in a new genus.

654 The analysis of SSUrRNA gene sequences indicates that $P$. dicentrarchi 655 obtained from turbot and fine flounder (I1, Pe5 and Pe7) and isolates YK2 and YS2 656 from olive flounder of Miamiensis avidus are the same ciliate species, suggesting 657 that the latter have been misidentified. Morphological analysis of all of these 658 isolates is therefore urgently required for their correct identification.

659 In conclusion, the aetiological agent of scuticociliatosis produced in the fine 660 flounder Paralichthys adspersus is the same as that described in the olive flounder 661 Paralichthys.olivaceus and the turbot S. maximus. Due to the lack of information 662 regarding the nucleotide sequence of the SSUrRNA gene in the type species of 663 Philasterides, we suggest that the name $P$. dicentrarchi should be maintained for the 664 species that causes scuticociliatosis in turbot and fine flounder.

665

666 ACKNOWLEDGEMENTS

667 We are grateful for the support provided by Jaime Pauro (Headship of Pacific 668 Aquaculture Deep Frozen S A-Perú-) and by Dr Violeta Flores and Marco Medina of 669 the IMERPA (Peru) for technical assistance with scuticociliate isolation. This study was 
670 financially supported by grant AGL2014-57125-R from the Ministerio de Economía y

671 Competitividad (Spain), by grant GPC2014/069 from the Xunta de Galicia (Spain) and

672 by PARAFISHCONTROL project. This project received funding from the European

673 Union's Horizon 2020 research and innovation programme under grant agreement No.

674 634429. This publication reflects the views only of the authors, and the European

675 Commission cannot be held responsible for any use, which may be made of the 676 information contained therein.

677

678 REFERENCES

679 Azad, I.S., Al-Marzouk, A., James, C.M., Almatar, S. and Al-Gharabally, H. 680 (2007). Scuticociliatosis-associated mortalities and histopathology of natural 681 infection in cultured silver pomfret (Pampus argenteus Euphrasen) in Kuwait. $682 \quad$ Aquaculture 262, 202-210.

683 Bart, D., Drenek, S., Fokin, S. and Berendonk, T.U. (2006). Intraspecific genetic 684 variation in Paramecium revealed by mitochondrial cytochrome c oxidase I 685 sequences. Journal of Eukaryotic Microbiology 53, 20-25.

686

687

688

689

690

691

692

693
Bonar, C.J., Garner, M.M., Weber, E.S., Keller, C.J., Murray, M., Adams, L.M.a and Frasca S. Jr. (2013). Pathologic findings in weedy (Phyllopteryx taeniolatus) and leafy (Phycodurus eques) seadragons. Veterinary Pathology 50, 368-376.

Bordier, C. (1981). Phase separation of integral membrane proteins in Triton X-114. The Journal of Biological Chemistry, 256,1604-1607.

Budiño, B., Lamas, J., Pata, M.P., Arranz, J.A., Sanmartín, M.L. and Leiro, J. (2011a). Intraspecific variability in several isolates of Philasterides dicentrarchi 
Budiño, B., Lamas, J., González, A., Pata, M.P., Devesa, S., Arranz, J.A. and Leiro, Parasitology 175, 260-272. fish farm. Aquaculture 322-323, 23-32.

de Waal, T. (2012). Advances in diagnosis of protozoan diseases. Veterinary Parasitology 189, 65-74.

Declercq, A.M., Chiers, K., Van den Broeck, W., Rekecki, A., Teerlinck, S., 705 Adriaens, D., Haesebrouck, F. and Decostere, A. (2014). White necrotic tail

di Cicco, E., Paradis, E., Stephen, C., Turba, M.E. and Rossi, G. (2013). Scuticociliatid ciliate outbreak in Australian potbellied sea horse, Hippocampus abdominalis (Lesson, 1827): clinical signs, histopathological findings, and treatment with metronidazole. Journal of Zoo and Wildlife Medicine 44, 435-440.

712 Dickerson, H.W., Clark, T.G. and Findly, R.C. (1989). Icththyophthirius multifiliis has membrane-associated immobilization antigens. The Journal of Protozoology 36, $159-164$.

Dragesco, A., Dragesco, J., Coste, F., Gasc, C., Romestand, B., Raymond, J. and Bouix, G. (1995). Philasterides dicentrarchi, n. Sp. (Ciliophora, Scuticociliatida), a histiophagous opportunistic parasite of Dicentrarchus labrax 
718 (Linnaeus, 1758), a reared marine fish. European Journal of Protistology 31, $719 \quad 327-340$.

720 Fan, X., Hu, X., Al-Farraj, S.A., Clamp, J.C. and Song W. (2011). Morphological 721

723 description of three marine ciliates (Ciliophora, Scuticociliatia), with establishment of a new genus and two species. European Journal of Protistology 47, 186-196.

Felsenstein, J. (1985). Confidence limits on phylogenies: and approach using the boostrap. Evolution 39, 783-791.

726 Fenchel, T. (1987). Adaptative significance of polymorphic life cycles in protozoa: resposes to starvation and reffeding in two species of marine ciliates. Journal of Experimental Marine Biology and Ecology 136, 159-177.

Fernández-Galiano, D. (1994). The ammoniacal silver carbonate method as a general

Gao, F., Fan, X., Yi, Z., Strüder-Kypke, M. and Song, W. (2010). Phylogenetic consideration of two scuticociliate genera, Philasterides and Boveria (Protozoa, Ciliophora) based on 18 S rRNA gene sequences. Parasitology International 59, $549-555$.

Gao, F., Katz, L.A. and Song W. (2012). Insights into the phylogenetic and taxonomy of philasterid ciliates (Protozoa, Ciliophora, Scuticociliatia) based on analyses of multiple molecular marker. Molecular Phylogenetics and Evolution 64, 308-317.

Gao, F., Katz, L.A. and Song, W. (2013). Multigene-based analyses on evolutionary phylogeny of two controversial ciliate orders: Pleuronematida and Loxocephalida (Protista, Ciliophora, Oligohymenophorea). Molecular Phylogenetics and Evolution 68, 55-63. 
743 Gómez-Saladín, E. and Small, E.B. (1993a). Oral morphogenesis of the microstome to 744 macrostome transformation in Miamiensis avidus strain Ma/2. Journal of 745 Eukaryotic Microbiology 40, 363-370.

746 Gómez-Saladin, E. and Small, E.B. (1993b). Starvation induces tomitogenesis in 747 Miamiensis avidus strain Ma/2. Journal of Eukaryotic Microbiology 40, 727-730. 748 Grolière, C.A. (1980). Morphologie et stomatogenèse chez deux ciliés Scuticociliatida des 749 750 genres Phïlasterides Kahl, 1926 et Cyclidium O. F. Müller; 1786. Acta Protozoologica 19, 195-206.

751 Harikrishnan, R., Balasundaram, C. and Heo, M.S. (2010). Scuticociliatosis and its 752 753 recent prophylactic measures in aquaculture with special reference to South Korea Taxonomy, diversity and diagnosis of scuticociliatosis: Part I Control strategies of scuticociliatosis: Part II. Fish and Shellfish Immunology 29, 15-31.

Harikrishnan, R., Jin, C.N., Kim, J.S., Balasundaram, C. and Heo, M.S. (2012). Philasterides dicentrarchi, a histophagous ciliate causing scuticociliatosis in olive flounder, Philasterides dicentrarchi-Histopathology investigations. Experimental Parasitology 130, 239-245.

Hu, X., Song, W. and Warren, A. (2009). Scuticociliatids. In. Free-living Ciliates in Bohai and Yellow Sea, China. (Song W., Warren A. \& Hu X. ,eds.) Science Press. Beijing.

762 Iglesias, R., Paramá, A., Álvarez, M.F., Leiro, J., Fernández, J. and Sanmartín, 763 M.L. (2001). Philasterides dicentrarchi (Ciliophora, Scuticociliatida) as the 764 causative agent of scuticociliatosis in farmed turbot, Scophthalmus maximus in 765 Galicia (NW Spain). Diseses of Aquatic Organisms 46, 47-55. 
766 Iglesias, R., Paramá, A., Álvarez, M.F., Leiro, J., Aja, C. and Sanmartín, M.L. 767 (2003a). In vitro growth requeriments for the fish pathogen Philasterides 768 dicentrarchi (Ciliophora, Scuticociliatida). Veterinary Parasitology 111, 19-30.

769 Iglesias, R., Paramá, A., Álvarez, M.F., Leiro, J., Ubeira, F.M. and Sanmartín, 770 M.L. (2003b). Philasterides dicentrarchi (Ciliophora: Scuticociliatida) express 771 surface immobilization antigens that probably induce protective immune 772 responses in turbot. Parasitology 126, 125-134.

773 Ito, H., Fukuda, Y., Murata, K. and Kimura, A. (1983). Transformation of intact 774 yeast cells treated with alkali cations. Journal of Bacteriology 153, 163-168.

775 Jung, S.J., Kitamura, S.I., Song, J.Y., Joung, I.Y. and Oh, M.J. (2005). Complete 776 small subunit rRNA gene sequence of the scuticociliate Miamiensis 777 avidus pathogenic to olive flounder Paralichthys olivaceus. Diseases of Aquatic $778 \quad$ Organisms 64, 159-162.

779 Jung, S.J., Kitamura, S.I., Song, J.Y. and Oh, M.J. (2007). Miamiensis avidus 780 (Ciliophora: Scuticociliatida) causes systemic infection of olive flounder 781 Paralichthys olivaceus and is a senior synonym of Philasterides dicentrarchi. 782 Diseases of Aquatic Organisms 73, 227-234.

783 Jung, S.J., Im, E.Y., Struder-Kypke, M.C., Kitamura, S. and Woo, P.T. (2011). 784 Small subunit ribosomal RNA and mitochondrial cytochrome c oxidase subunit 7851 gene sequences of 21 strains of the parasitic scuticociliate Miamiensis avidus 786 (Ciliophora, Scuticociliatia). Parasitology Research 108, 1153-1161.

787 Kim, S.M., Cho, J.B., Kim, S.K., Nam, Y.K. and Kim, K.H. (2004a). Occurrence of 788 scuticociliatosis in olive flounder Paralichthys olivaceus by Philasterides 789 dicentrarchi (Ciliophora: scuticociliatia). Diseases of Aquatic Organisms 62, $790 \quad 2333-2338$. 
791 Kaneshiro, E.S., Dunham, P.B. and Holz, G.G. (1969). Osmorregulation in a marine 792 ciliate, Miamiensis avidus. I. Regulation of inorganic ions and water. The 793 Biological Bulletin 136, 65-75.

794 Kimura, M. (1980). A simple method for estimating evolutionary rates of base 795 substitutions through comparative studies of nucleotide sequences. Journal of 796 Molecular Evolution 16, 111-120.

797 Kumar, S., Stecher, G., and Tamura, K. (2016). MEGA7: Molecular Evolutionary 798 Genetics Analysis version 7.0 for bigger datasets. Molecular Biology and $799 \quad$ Evolution 33: 1870-1873.

800 Leiro, J., Siso, M.I., Paramá, A., Ubeira, F.M. and Sanmartín, M.L. (2000). RFLP 801 analysis of PCR-amplified small subunit ribosomal DNA of three fish 803 microsporidian species. Parasitology 124, 145-151.

Long, H. and Zufall, R.A. (2010). Diverse modes of reproduction in the marine free804 living ciliate Glauconema trihymene. BioMed Central Microbiology 10, 108.

López-López, O., Fuciños, P., Pastrana, L., Rúa, M.L., Cerdán, M.E. and González-Siso, M.I. (2010). Heterologous expression of an esterase from 808 Thermus thermophilus HB27 in Saccharomyces cerevisiae. Journal of Biotechnology 145, 226-232.

Lynn, D.H. and Strüder-Kypke, M. (2005). Scuticociliate endosymbionts of echinoids (phylum Echinodermata): phylogenetic relationships among species in the genera Entodiscus, Plagiopyliella, Thyrophylax, and Entorhipidium (phylum Ciliophora). The Journal of Parasitology 91, 1190-1199.

McWilliam, H., Li, W., Uludag, M., Squizzato, S., Park, Y.M., Buso, N., Cowley, 814 A.P., and López, R. (2013). Analysis tool web services from the EMBL-EBI. 815 Nucleic Acids Research 41(Web Server issue), W597-W600. 
816 Mallo, N., Lamas, J. and Leiro, J.M. (2013). Evidence of an alternative oxidase 817 pathway for mitochondrial respiration in the scuticociliate Philasterides 818 dicentrarchi. Protist 164, 824-836.

819 Mallo, N., Lamas, J., Piazzon, C. and Leiro, J.M. (2015). Presence of a plant-like 820 proton-translocating pyrophosphatase in a scuticociliate parasite and its role as a 821 possible drug target. Parasitology 142, 449-462.

822 Mallo, N., Lamas, J., Defelipe, A.P., Decastro, M.E., Sueiro, R.A. and Leiro, J.M. 823 (2016). Presence of an isoform of $\mathrm{H}+$-pyrophosphatase located in the alveolar 824 sacs of a scuticociliate parasite of turbot: physiological consequences. $825 \quad$ Parasitology 143, 576-587.

826 Miao, M., Warren, A., Song, W., Wang, S., Shang, H. and Chen, Z. (2008). Analysis 827 of internal transcribed spacer 2 (ITS2) region of scuticociliates and related taxa 828 (Ciliophora, Oligohymenophorea) to infer their evolution and phylogeny. Protist $829 \quad \mathbf{1 5 9}, 519-533$.

830 Miao, M., Wang, Y., Song, W., Clamp, J. C., and Al-Rasheid, K. A. S. (2010). 831 Description of Eurystomatella sinica n. gen., n. sp., with establishment of a new 832 family Eurystomatellidae n. fam. (Protista, Ciliophora, Scuticociliatia) and 833 analyses of its phylogeny inferred from sequences of the small-subunit rRNA 834 gene. International Journal of Systematic and Evolutionary Microbiology 60, $835 \quad 460-468$

836 Moewus, L. (1963). Studies on a marine parasitic ciliate as a potential virus vector. In: 837 Symp. on Marine Microbiology. pp. 366-379. C.H. Oppenheimer (Ed.), Charles $838 \quad$ C. Thomas, Springfield, Ill. 
839 Morais, P., Lamas, J., Sanmartín, M.L., Orallo, F. and Leiro, J. (2009).

840 Resveratrol induces mitochondrial alterations, autophagy and a cryptobiosis841 like state in scuticociliates. Protist 160, 552-564.

842 Moustafa, E.M.M., Naota, M., Morita, T., Tange, N. and Shimada, A. (2010). 843 Pathological study on the scuticociliatosis affecting farmed Japanese flounder 844 (Paralichthys olivaceus) in Japan. The Journal of Veterinary Medical Science 72, $845 \quad 1359-1362$.

846 Munday, B.L., O’Donoghue, P.J., Watts, M., Rough, K. and Hawkesford, T. (1997).

847 Fatal encephalitis due to the scuticociliate Uronema nigricans in sea-caged, 848 southern bluefin tuna Thunnus maccoyii. Diseases of Aquatic Organisms 30, 1784925.

850 Ofelio, C., Blanco, A., Roura, A., Pintado, J., Pascual, S. and Planas, M. (2014). 851 Isolation and molecular identification of the scuticociliate Porpostoma notata 852 Moebius, 1888 from moribund reared Hippocampus hippocampus (L.) seahorses, 853 by amplification of the SSU rRNA gene sequences. Journal of Fish Diseases 37, $854 \quad 1061-1065$.

855 Pan, X., Zhu, M., Ma, H., Al-Rasheid, K.A. and Hu, X. (2013). Morphology and 856 small-subunit rRNA gene sequences of two novel marine ciliates, Metanophrys 857 orientalis spec. nov. and Uronemella sinensis spec. nov. (Protista, Ciliophora, 858 Scuticociliatia), with an improved diagnosis of the genus Uronemella. 859 International Journal of Systematic and Evolutionary Microbiology 63, 3515-23.

860 Paramá, A., Iglesias, R., Álvarez, M.F., Leiro, J., Aja, C. and Sanmartín, M.L. 861 (2003). Philasterides dicentrarchi (Ciliophora, Scuticociliatida): experimental 862 infection and posible routes of entry in farmed turbot (Scophthalmus maximus). $863 \quad$ Aquaculture 217, 73-80. 
864 Paramá, A., Arranz, J.A., Álvarez, M.F., Sanmartín, M.L. and Leiro, J. (2006).

865 Ultrastructure and phylogeny of Philasterides dicentrarchi (Ciliophora:

866 Scuticociliatia) from farmed turbot in NW Spain. Parasitology 132, 555-564.

867 Paramá, A., Castro, R., Lamas, J., Sanmartín, M.L., Santamarina, M.T., and Leiro,

868 J. (2007). Scuticociliate proteinases may modulate turbot immune response by 869 inducing apoptosis in pronephric leucocytes. International Journal for $870 \quad$ Parasitology 37, 87-95.

871 Piazzon, C., Lamas, J., Castro, R., Budiño, B., Cabaleiro, S., Sanmartín, M.L., and 872 Leiro, J. (2008). Antigenic and cross-protection studies on two turbot 873 scuticociliate isolates. Fish and Shellfish Immunology 25, 417-424.

874 Piazzon, C., Lamas, J. and Leiro, J.M. (2011). Role of scuticociliate proteinases in 875 infection success in turbot, Psetta maxima (L.). Parasite Immunology 33, 535876544.

877 Ramos, M.F., Costa, A.R., Barandela, T., Saraiva, A. and Rodrigues, P.N. (2007).

878 Scuticociliate infection and pathology in cultured turbot Scophthalmus maximus 879 from the north of Portugal. Diseases of Aquatic Organisms 74, 249-253.

880 Rossteucher, S., Wenker, C., Jermann, T., Wahli, T., Oldenberg, E. and Schmidt881 Posthaus, H. (2008). Severe scuticociliate (Philasterides dicentrarchi) infection 882 in a population of sea dragons (Phycodurus eques and Phylopteryx taeniolatus). 883 Veterinary Parasitology 45, 546-550.

884 Schmidt, S.L., Benhart, D., Schlegel, M. and Fried, J. (2006). Fluorescence in situ 885 with specific oligonucleotide rRNA probes distinguishes the sibling species 886 Stylonychia lemnaea and Stylonychia mytilus (Ciliophora, Spirotrichea). Protist 887 157, 21-30. 
888 Shin, P.S., Han, J.E., Gómez, D.K., Kim, J.H., Choresca, Jr. C.H., Jun, J.W., and 889 Park, S.C. (2011). Identification of scuticociliate Philasterides dicentrarchi 890 from indo-pacific seahorses Hippocampus kuda. African Journal of $891 \quad$ Microbiology Research 5, 738-741.

892 Sievers, F., Wilm, A., Dineen, D., Gibson, T.J., Karplus, K., Li, W., López, 893 R., McWilliam, H., Remmert, M., Söding, J., Thompson, J.D. and Higgins, 894 D.G. (2011). Fast, scalable generation of high-quality protein multiple sequence 895 alignments using Clustal Omega. Molecular Systems Biology 7, 539.

896 Saitou, N. and Nei M. (1987). The neighbor-joining method: A new method for 897 reconstructing phylogenetic trees. Molecular Biology and Evolution 4, 406-425.

898 Small, E.B. (1967). The scuticociliatida, a new Order onf the Class Ciliatea (Phylum 899 Protozoa, Subphylum Ciliophora). Transactions of the American Microscopical $900 \quad$ Society 86, 345-370.

901 Small, H.J., Neil, D.M., Taylor, A.C., Bateman, K. and Coombs, G.H. (2005). A 902 parasitic scuticociliate infection in the Norway lobster (Nephrops norvegicus). 903 Journal of Invertebrate Pathology 90, 108-117.

904 Smith, P.J., McVeagh, S.M., Hulston, D., Anderson, S.A. and Gublin, Y. (2009). 905 DNA identification of ciliates associated with disease outbreaks in a New 906 Zealand marine fish hatchery. Diseases of Aquatic Organisms 86, 163-167.

907 Soldo, A.T. and Merlin, E.J. (1972). The cultivation of symbiont-free marine ciliates 908 in axenic medium. The Journal of Protozoology 19, 519-524.

909 Song, W.B. and Wilbert, N. (2000). Redefinition and redescription of some marine 910 scuticociliates from China, with report of a new species, Metanophrys siensis 911 nov. Spec. (Ciliophora, Scuticociliatida). Zoologischer Anzeiger 239, 45-74. 
912 Song, J.Y., Kitamura, S., Oh, M.J., Kang, H.S., Lee, J.H., Tanaka, S.J., and Jung,

913 S.J. (2009a). Pathogenicity of Miamiensis avidus (syn. Philasterides

914 dicentrarchi), Pseudocohnilembus persalinus, Pseudocohnilembus hargisi

915 and Uronema marinum (Ciliophora, Scuticociliatida). Diseases of Aquatic

$916 \quad$ Organisms 83, 133-143.

917 Song, J.Y., Sasaki, K., Okada, T., Sakashita, M., Kawahami, H., Matsuoka, S., Kan,

918 H.S., Nakayama, K., Jung, S.J., Oh, M.J. and Kitamura, S.I. (2009b).

919 Antigenic differences of the scuticociliate Miamiensis avidus from Japan.

$920 \quad$ Journal of Fish Disesases 32, 1027-1034.

921 Stidworthy, M.F., Garner, M.M., Bradway, D.S., Westfall, B.D., Joseph, B., 922 Repetto, S., Guglielmi, E., Schmidt-Posthaus, H. and Thornton, S.M. (2014).

923 Nondomestic, exotic, wildlife and zoo animals systemic scuticociliatosis 924 (Philasterides dicentrarchi) in sharks. Veterinary Pathology 51, 628-663.

925 Stoeck, T., Welter, H., Seitz-Bender, D., Kusch, J.and Schmidt, H.J. (2000).

926 ARDRA and RAPD-fingerprint reject the sibling species concept for the ciliate 927 Paramecium caudatum (Ciliophora, Protoctista). Zoologica Scripta 29, 75-82.

928 Thompson, J.C., and Moewus, L. (1964). Miamiensis avidus n. g., n. sp., a marine 929 facultative parasite in the ciliate order Hymenostomatida. The Journal of $930 \quad$ Protozoology 11, 378-381.

931 Umehara, A., Kosuga, Y. and Hirose, H. (2003). Scuticociliata infection in the weedy 932 sea dragon Phyllopteryx taeniolatus. Parasitology International 52, 165-168.

933 Whang, I., Kang, H.S. and Lee, J. (2013). Identification of scuticociliates 934 (Pseudocohnilembus persalinus, P. longisetus, Uronema marinum and 935 Miamiensis avidus) based on the cox1 sequence. Parasitology International 62, $936 \quad 7-13$. 


\section{Figures and Table legends}

938 Figure 1. Paralichthys adspersus: clinical signs of infection. (A) Visible changes are 939 observed in the pigmentation of infected fish, and (B) the presence of 940 haemorrhagic lesions on the gills. (C) Ciliates obtained from ascites liquid. 941 Histopathological findings of the infection by scuticociliates: (D) Histological 942 section of gills showing the presence of ciliates (arrows), and (E) microphotograph showing a massive infection of ciliates in the myocardium (arrows) causing intense cardiac muscle histophagy. Staining H\&E, scale bar $=$ $50 \mu \mathrm{M}$.

Figure 2. Morphological characteristics of isolates Pe5 and Pe7 from farmed flounder Paralichthys adspersus in comparison with those of Miamiensis avidus strain $\mathrm{Ma} / 2\left(\mathrm{ATCC}^{\circledR} 50180^{\mathrm{TM}}\right)$. Silver carbonate-impregnated trophozoites: isolate Pe5 $(\mathrm{A}, \mathrm{B})$; isolate $\mathrm{Pe} 7(\mathrm{~F}, \mathrm{G})$; and Miamiensis avidus strain $\mathrm{Ma} / 2\left(\mathrm{ATCC}^{\circledR} 50180^{\mathrm{TM}}\right)$ $(\mathrm{J}, \mathrm{M}, \mathrm{N}) .(\mathrm{A}, \mathrm{F})$ Light micrographs showing the oral ciliature and the posterior cell portions $(B, G)$ of isolates Pe5 and Pe7, respectively. $(C, D, H)$ Schematic drawings of the buccal apparatus in Philasterides dicentrarchi from sea bass (C), Pe5 (D), and Pe5 (H), showing three oral polykinetids, (M1, M2 and M3) and two paraoral membrane (PM1 and PM2) (E, I) Drawings of posterior ends of isolates Pe5 and Pe7 showing 12 kineties (1-12), the pore of the subterminal contractile vacuole (VP), and a prominent caudal cilium (C, circle). (J) Light microphotograph of silver carbonate-impregned specimens of $M$. avidus strain $\mathrm{Ma} / 2$ showing the buccal apparatus. $(\mathrm{K}, \mathrm{L})$ Drawings of oral ciliature in $M$. avidus from original description $(\mathrm{K})$ and strain $\mathrm{Ma} / 2$ (L) showing the oral polykinetids $\mathrm{M} 1, \mathrm{M} 2$ and $\mathrm{M} 3$, and the paraoral membrane (PM). (M) Microphotograph of a trophozoite of $M$. avidus strain $\mathrm{Ma} / 2$ showing the spine- 
shaped apical cell portion (arrow). (N, O) Tomites of $M$. avidus strain $\mathrm{Ma} / 2$ stained with silver-carbonate $(\mathrm{N})$, and in vivo under phase contrast optics $(\mathrm{O})$. Scale bars $=10 \mu \mathrm{m}$.

965 Figure 3. Structure of nuclear apparatus. Confocal microscope photomicrographs (A, B,

966 D) of trophozoites stained with DAPI, and ligh micrographas of cells stained 967 with silver carbonate (C), showing the position of the macronucleus (M) and 968 micronucleus (m): (A) strain I1 of Philasterides dicentarchi, (B) isolate Pe5, (C) 969 isolate Pe7, and (D) strain Ma/2 of Miamiensis avidus. Figure C also shows the 970 caudal cilium (c) and the posterior contractile vacuole (cv). Scale bars $=10 \mu \mathrm{m}$.

971 Figure 4. Induction of tomitogenesis in M. avidus and P. dicentrarchi under conditions

975 Figure 5. (A) Prey-induced transformation of $M$. avidus $\mathrm{ATCC}^{\circledR} 50180^{\mathrm{TM}}$ (strain $\left.\mathrm{Ma} / 2\right)$ co-cultivated with the I1 strain from Philasterides dicentrarchi in non-nutrient artificial seawater (NSS). (A-D) Macrostome formation at day 2 of co-cultures showing ciliates ingested in its interior (circles and arrows). (A) Silver staining, (B) phase contrast, (C) acridine orange staining, (D) DAPI staining. (E) Polymerase chain reaction from genomic DNA of $M$. avidus (M), $P$. dicentrarchi strain I1 (I1), and M. avidus and P.dicentrarchi (M+I1) cocultivated for five days. (F) Primers designed from the nucleotide sequences of $P$. dicentrarchi corresponding to (a) the $\alpha$-tubulin, (b) $\beta$-tubulin and (c) the small rRNA subunit (SSUrRNA) gene used for PCR. Mw: molecular size markers.

Figure 6. Virulence of the Ma / 2 strain of $M$. avidus $\mathrm{ATCC}^{\circledR} 50180^{\mathrm{TM}}$ in experimentally infected turbot. (A) Abdominal distension due to accumulation 
987

988

989

990

991

992

of ascitic fluid in the body cavity. The arrow indicates anal inflammation. (B) Kinetics of cumulative mortality induced after intraperitoneal injection with $M$. avidus five after infection.

Figure 7. Neighbour-joining (NJ) unrooted trees inferred from: SSUrRNA (A), as well as, the $\alpha$ - (B), and $\beta$-tubulin (C) nucleotide sequences showing the phylogenetic relationships between isolates Pe5 and Pe7 from the fine flounder, strain I1 of Philasterides dicentrarchi isolated from turbot, and strain Ma/2 of Miamiensis avidus ATCC $^{\circledR} 50180^{\mathrm{TM}}$. The phylogeny was also inferred by analysis of SSUrRNA gene sequences between the isolates from the fine flounder, strains of Philsterides isolated from turbot, strains of Miamiensis isolated from olive flounder (strains YK2 and YS2), isolate FXP2009050602 of M. avidus, and several species of philasterids (see Table 1) including strain GF200806601 of Philasterides armatalis (A). Nodes represent bootstrap values of 1000 resampled values in the $\mathrm{NJ}$ analysis with the Kimura two-parameter correction model, and the scale bar indicates the genetic distance.

Figure 8. Analysis of the antigenic relationships related to the alpha subunit of tubulin, using a gene fragment (A) between isolates from the fine flounder P. adspersus, Philasterides dicentarchi strain I1 and Miamiensis avidus strain Ma/2 (ATCC ${ }^{\circledR}$ $\left.50180^{\mathrm{TM}}\right)$, by various immunoassays using antibodies generated against a fragment of recombinant $\alpha$-tubulin. Immunopattern recognition by immunofluorescence: (B) vs. P. dicentrarchi strain I1 (confocal microscope image using a combined DAPI staining and staining with FITC), (C) vs. the Pe5 isolate (D) and the Pe7 isolate from the fine flounder P. adspersus and, (E) vs. M. avidus strain Ma/2. (F) ELISA of the degree of cross-reactivity between $\alpha$ tubulin from $P$. dicentrarchi strain I1, isolate Pe7 from the fine flounder $P$. 
1012

1013

1014

1015

1016

1017

1018

1019

1020

1021

1022

1023

1024

1025

1026

1027

1028

1029

1030

1031

1032

1033

1034

1035

1036

adspersus and $M$. avidus strain $\mathrm{Ma} / 2$. The results are expressed as mean values of the absorbance at $492 \mathrm{~nm} \pm$ standard error $(\mathrm{n}=5)$, and asterisks indicate the statistical significance $(P<0.01)$. $(\mathrm{G})$ Western blot analysis of ciliary proteins of M. avidus strain $\mathrm{Ma} / 2$ (lane 1), P. dicentrachi strain I1 (lane 2) and the Pe7 isolate from $P$. adspersus showing two bands of recognition corresponding to two polypeptide fragments of $\alpha$-tubulin (arrows). Mw: molecular weight markers expressed in $\mathrm{kD}$.

Table 1. List of philasterid species included in the phylogenetic analysis, showing the GenBank Accession numbers for their SSUrRNA gene sequences, the isolates/strains, host specificity, and sequence length in base pairs (bp).

Table 2. Biometric data for silver-impregnated ciliates isolates (Pe5 and Pe7) from Paralichthys adspersus, Philasterides dicentrarchi strain I1 isolated from turbot, P. dicentarchi (Dragesco et al., 1995) from seabass, strains T5 and T16 of Miamiensis avidus (Thompson and Moewus 1964), and strain Ma/2 of M. avidus $\left(\mathrm{ATCC}^{\circledR} 50180^{\mathrm{TM}}\right)$. *Biometric values obtained from specimens of $M$. avidus supplied by ATCC and cultured in our laboratory. ${ }^{\ddagger}$ Data obtained from microstomes. The values shown are expressed (in $\mu \mathrm{m}$ ) as mean \pm standard error, with the minimum-maximum ranges in parentheses. M1-M3: oral polykinetids, PM: paroral membrane; PM1, PM2: paroral membranes 1 and 2. CVP: contractile vacuole pore; Kn: kinety. The measurements were made in 50 specimens. (-) No data available.

Table 3. Nucleotide identity percentage analyzed by the BLAST alignment program between regions of DNA gene of the small subunit of (A) rRNA (SSUrRNA) and (B) $\alpha$ - and $\beta$-subunits of tubulin of isolates Pe5 and Pe7 from the fine flounder Paralichthys adspersus, strain I1 of Philasterides dicentrarchi isolated 
1037 from turbot and strain Ma/2 of Miamiensis avidus held in $\mathrm{ATCC}^{\circledR} 50180^{\mathrm{TM}}$. 1038 Additionally, the BLAST analysis of the SSUrRNA sequences included the 1039 strains YK2 and YS2 of Miamiensis avidus isolated from Paralichthys olivaceus, 1040 and the GF2008082801 strain of Philasterides armatalis. 


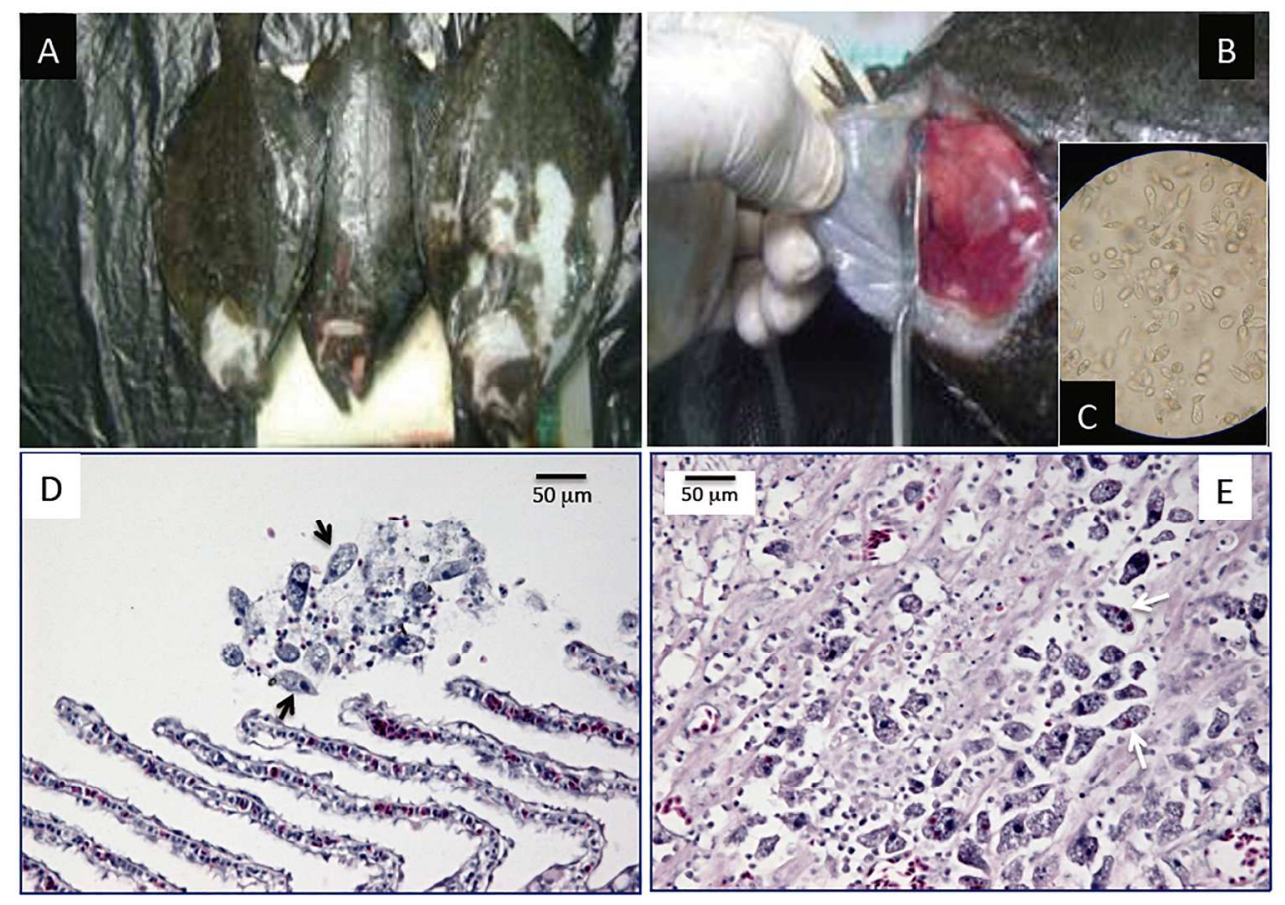

Figure 1

$209 \times 150 \mathrm{~mm}(300 \times 300$ DPI $)$ 

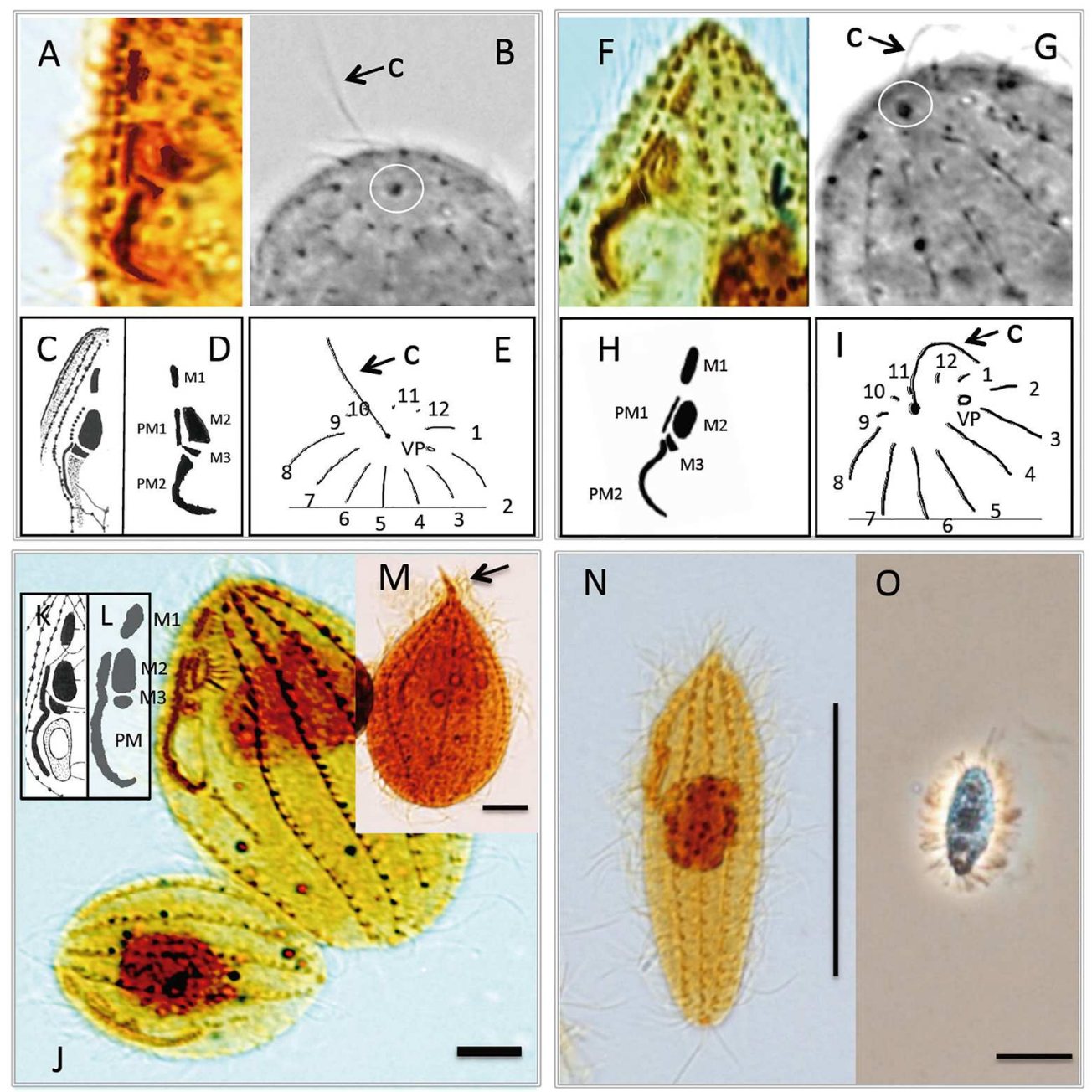

Figure 2

$209 \times 214 \mathrm{~mm}(300 \times 300$ DPI $)$ 


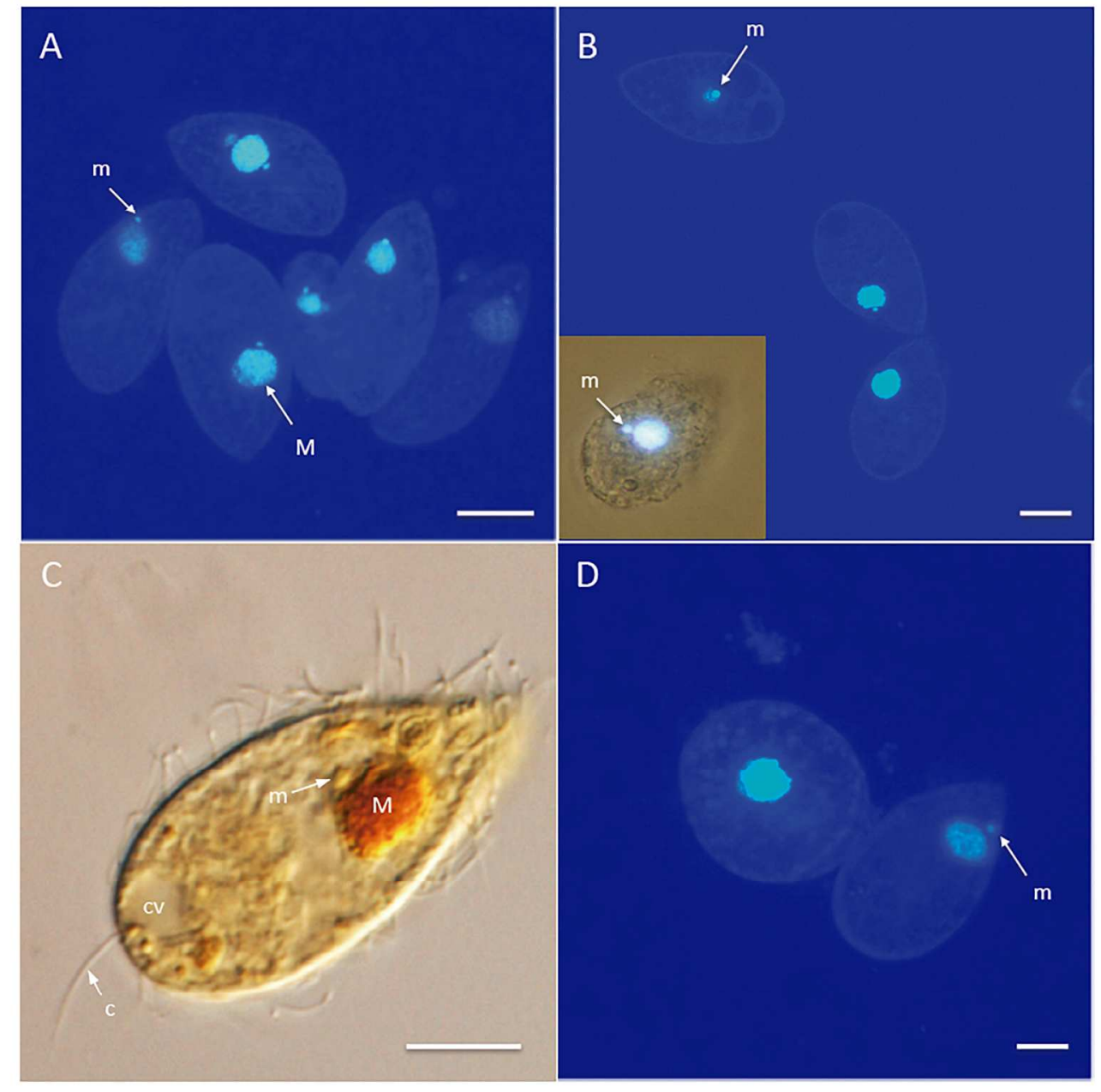

Figure 3

$209 \times 210 \mathrm{~mm}(300 \times 300$ DPI $)$ 


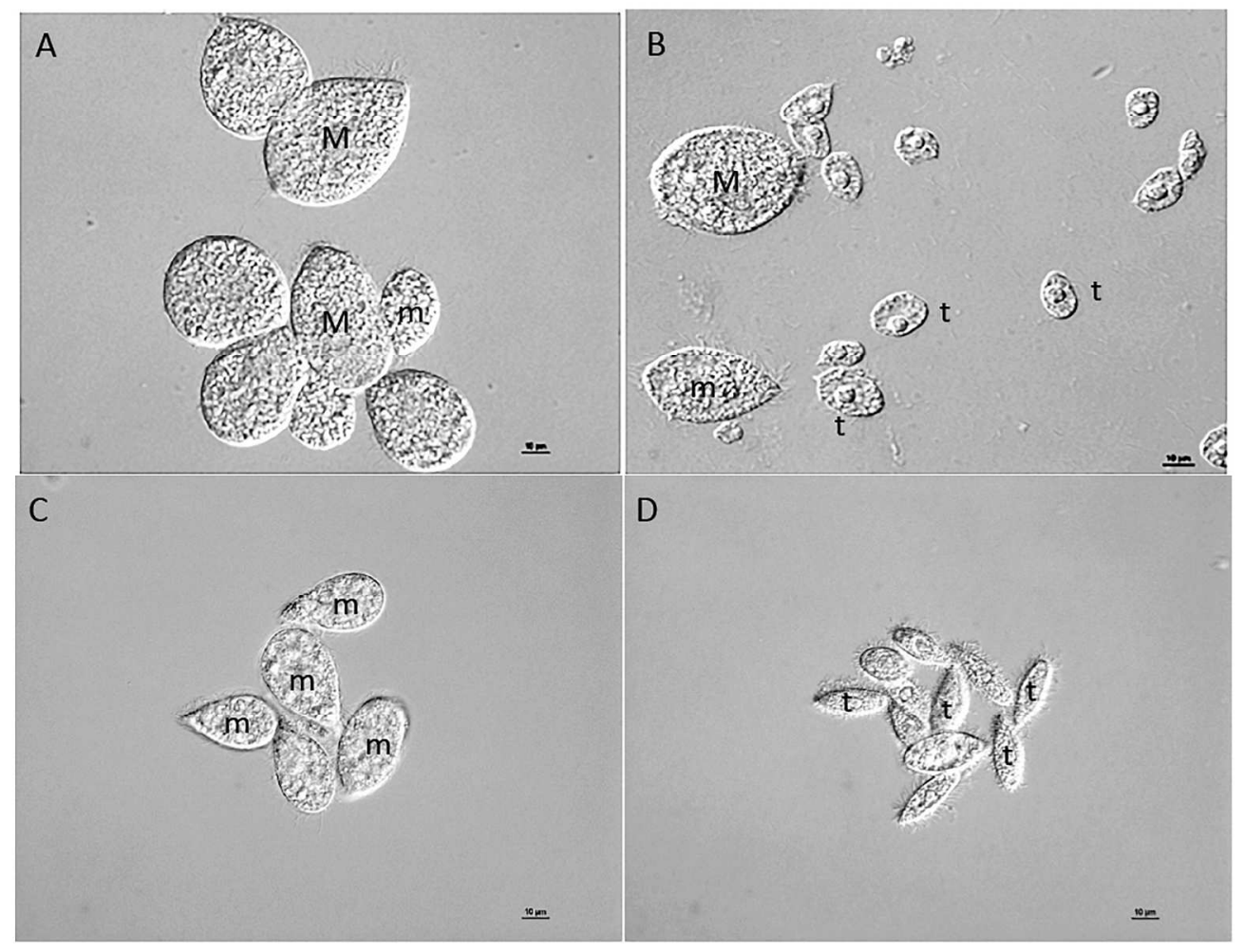

Figure 4

$209 \times 162 \mathrm{~mm}(300 \times 300$ DPI) 

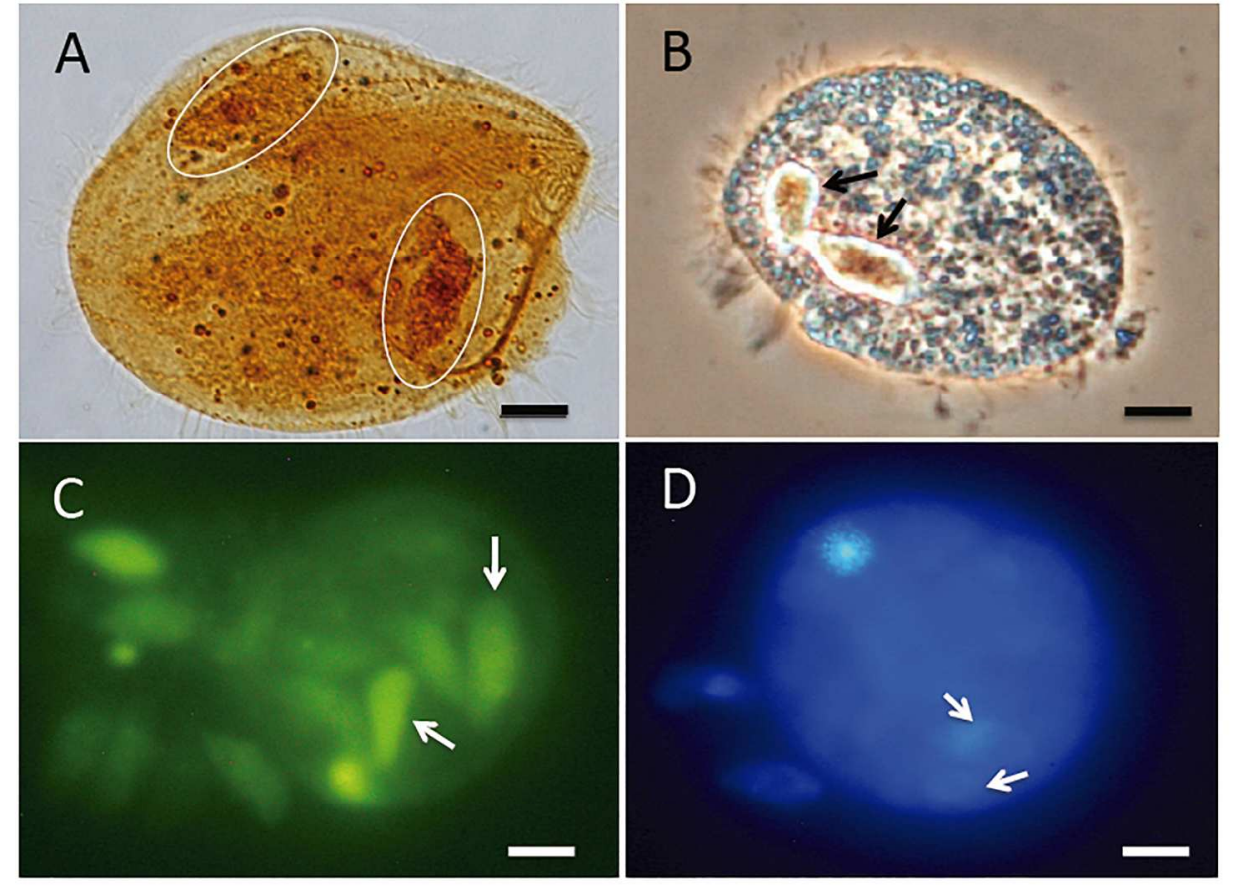

\begin{tabular}{|c|c|c|c|c|c|c|}
\hline E) $\mathrm{Mw}$ & $M+11$ & $M$ & 11 & F) Gene & Sequence forward/reverse $\left(5^{\prime}-3^{\prime}\right)$ & Size fragment (bp) \\
\hline$\underline{E}$ & & & 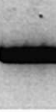 & $\alpha$-tubulin & $\begin{array}{l}\text { TTTAGAACCCACCGTTATTGA } \\
\text { TGATTCTGTCTAAGCATAA }\end{array}$ & 161 \\
\hline b) & & & - & $\beta$-tubulin & $\begin{array}{l}\text { CAATAAGGTTCCCATTCC } \\
\text { TAATTAATAAAAAATAATTCA }\end{array}$ & 259 \\
\hline$=$ & 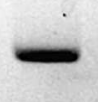 & & & SSUrRNA & $\begin{array}{l}\text { GAGAAACGGCTACCACATCTA } \\
\text { CAGGTAAAGAGCCTACTCCA }\end{array}$ & 349 \\
\hline
\end{tabular}

Figure 5

$209 \times 220 \mathrm{~mm}(300 \times 300$ DPI $)$ 

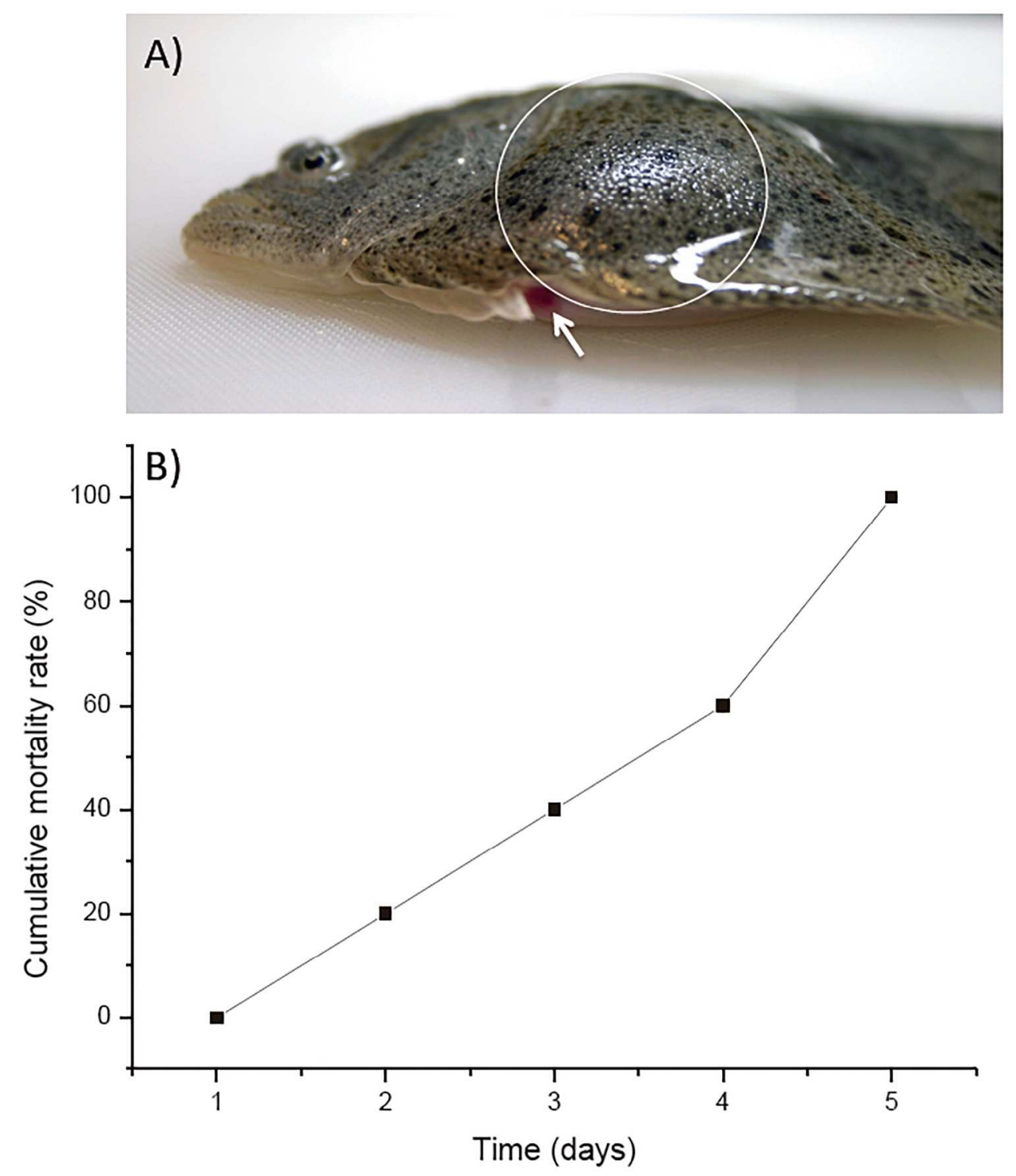

Figure 6

$209 \times 242 \mathrm{~mm}(300 \times 300$ DPI $)$ 
A)

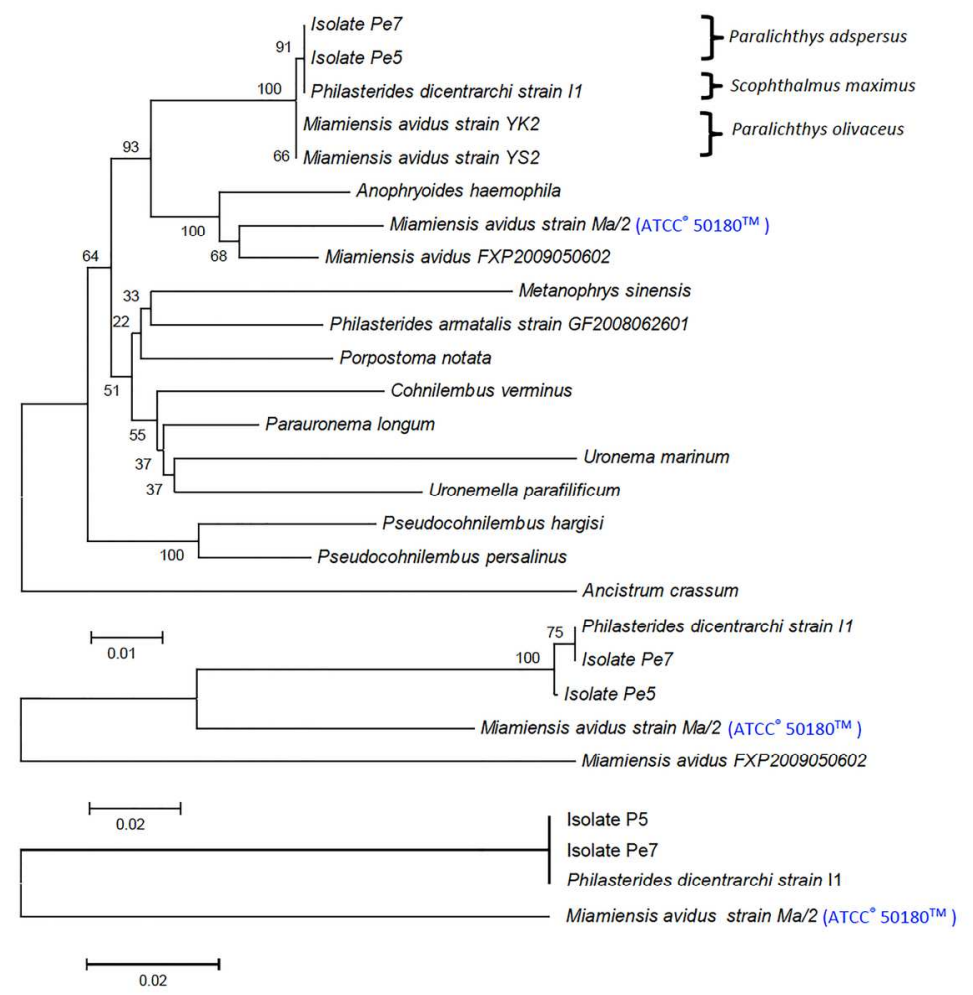

Figure 7

$167 \times 133 \mathrm{~mm}(300 \times 300 \mathrm{DPI})$ 

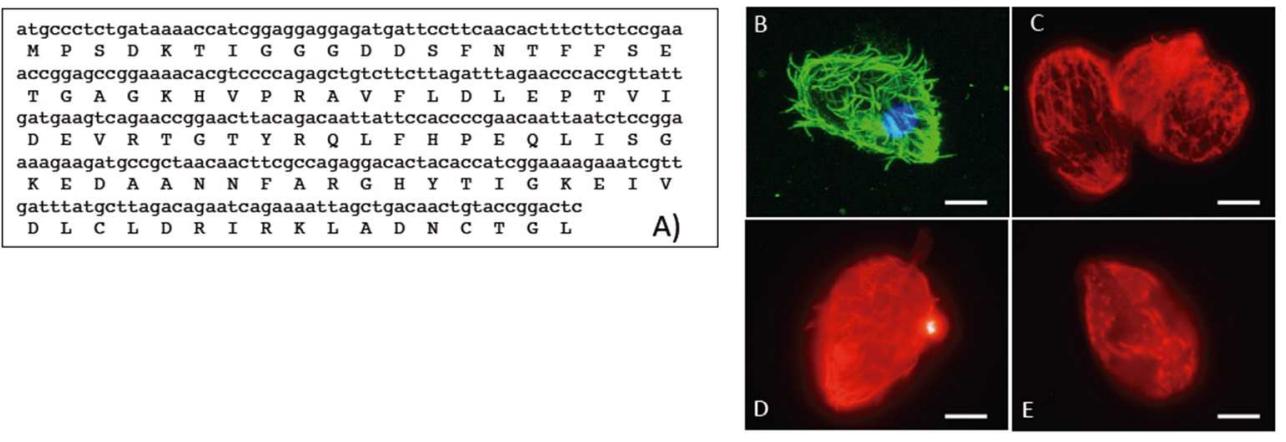

F)

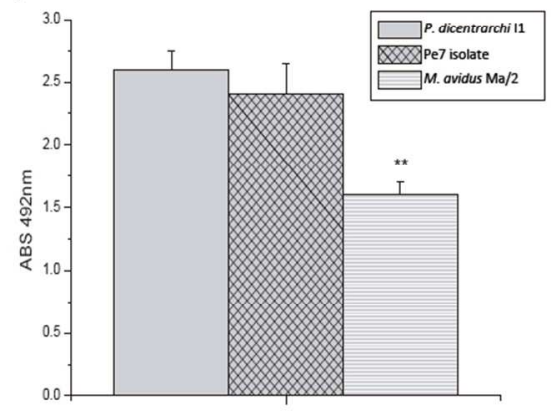

G)

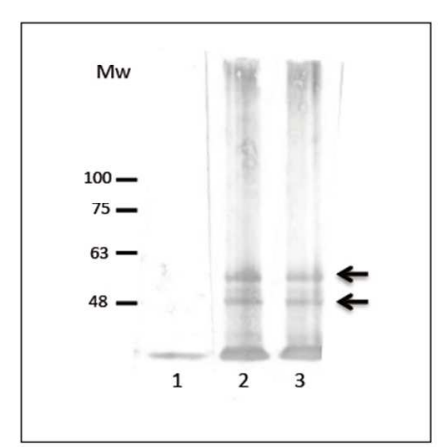

Figure 8

$87 \times 64 \mathrm{~mm}(300 \times 300$ DPI $)$ 


\begin{tabular}{|c|c|c|c|c|}
\hline Species & Accession number & Isolate/strain & Host & Size (bp) \\
\hline Ancistrum crassum & HM236340 & FXP2009051101 & - & 1753 \\
\hline Anophryoides haemophila & U51554.1 & - & $\begin{array}{c}\text { Lobster, } \\
\text { Homarus americanus }\end{array}$ & 1763 \\
\hline Metanophrys sinensis & HM236336 & FXP2009052901 & - & 1554 \\
\hline Miamiensis avidus ATCC $^{\circ} 50180^{\mathrm{TM}}$ & KX357144 & $\mathrm{Ma} / 2$ & Seahorses & 1759 \\
\hline Miamiensis avidus & EU831208 & YK2 & $\begin{array}{c}\text { Olive flounder, Paralichthys } \\
\text { olivaceus }\end{array}$ & 1759 \\
\hline Miamiensis avidus & EU831200 & YS2 & $\begin{array}{c}\text { Olive flounder, Paralichthys } \\
\text { olivaceus }\end{array}$ & 1759 \\
\hline Miamiensis avidus & JN885091.1 & FXP2009050602 & - & 1760 \\
\hline Parauronema longum & HM236338 & FXP200903150 & - & 1759 \\
\hline Philasterides dicentrarchi & JX914665 & 11 & Turbot, Scophthalmus maximus & 1759 \\
\hline Philasterides armatalis & FJ848877 & GF2008062601 & - & 1758 \\
\hline Porpostoma notata & HM236335 & FXP2009050601 & $\begin{array}{c}\text { Seahorses, Hippocampus } \\
\text { hippocampus }\end{array}$ & 1755 \\
\hline Pseudocohnilembus hargisi & AY833087 & SCL-B & $\begin{array}{c}\text { Olive flounder, Paralichthys } \\
\text { olivaceus }\end{array}$ & 1752 \\
\hline Pseudocohnilembus persalinus & AY835669 & SCL-A & $\begin{array}{c}\text { Olive flounder, Paralichthys } \\
\text { olivaceus }\end{array}$ & 1754 \\
\hline Uronema marinum & GQ465466 & PHB090219 & Marine fishes & 1758 \\
\hline Uronemella parafilificum & HM236337 & FXP2009053001 & - & 1756 \\
\hline
\end{tabular}




\begin{tabular}{|c|c|c|c|c|c|c|c|}
\hline Characteristics & Pe5 isolate & Pe7 isolate & $\begin{array}{c}\text { Philasterides } \\
\text { dicentrarchi strain } \\
\text { I1 }\end{array}$ & $\begin{array}{c}\text { Philasterides } \\
\text { dicentrarchi }\end{array}$ & \multicolumn{2}{|c|}{$\begin{array}{l}\text { Miamiensis } \\
\text { avidus }\end{array}$} & $\begin{array}{c}\text { Miamiensis } \\
\text { avidus strain } \mathrm{Ma} / 2^{*}\end{array}$ \\
\hline Length $^{\dagger}$ & $39.5 \pm 4.5(25-48)$ & $34.6 \pm 5.9(25-51)$ & $33.6 \pm 4.2(25-43)$ & $35.1 \pm 4.8(23-43)$ & 31.9 & 39.9 & $40.2 \pm 4.2(34-46)$ \\
\hline $\operatorname{Width}^{\dagger}$ & $21.5 \pm 3.7(16-28)$ & $19.6 \pm 3.8(12-29)$ & $19.5 \pm 3.0(15-28)$ & $18.5 \pm 2.5(12-25)$ & 16.1 & 20.1 & $23.4 \pm 2.6(18-28)$ \\
\hline \multicolumn{8}{|l|}{ Size of nuclei } \\
\hline Macronucleus & $5.4 \pm 0.8(4-6)$ & $5.9 \pm 1.2(3-8)$ & $7.0 \pm 1.0(5-9)$ & $6.4 \pm 1.1(4-8)$ & 4.1 & 5.1 & $13.2 \pm 2.6(6-17)$ \\
\hline Micronucleus & $1.0 \pm 0.2(0.6-1.2)$ & $1.2 \pm 0.3(0.7-1.6)$ & $1.6 \pm 0.2(1.3-1.9)$ & $1.5 \pm 0.2(1.2-1.8)$ & Exist & Exist & $1.7 \pm 0.3(1.4-2.0)$ \\
\hline \multicolumn{8}{|l|}{ Somatic cilia } \\
\hline Total no. of kineties & $10-12$ & $10-13$ & $13-14$ & $14(13-15)$ & $10-12$ & $10-13$ & $9-11$ \\
\hline \multicolumn{8}{|l|}{ Oral ciliature } \\
\hline Dist. from apex to M1 & $3.0 \pm 1.1(1.6-4.3)$ & $3.5 \pm 0.6(3.03-4.6)$ & $3.9 \pm 0.5(2.5-5.0)$ & $3.7 \pm 0.7(3-5)$ & 3-4 & $3-4$ & $3.3 \pm 1.9(1.4-10.9)$ \\
\hline Length of buccal field & $14.4 \pm 2.4(9.2-17.6)$ & $12.8 \pm 2.2(8.6-18.3)$ & $18.8 \pm 1.3(15.3-22.1)$ & - & 13.6 & 17.1 & $17.7 \pm 3.1(8.9-23.9)$ \\
\hline Lenght of PM1 & $3.2 \pm 0.5(2.4-3.9)$ & $3.1 \pm 1.3(2.2-4.3)$ & $3.7 \pm 0.5(2.5-4.8)$ & $4.1 \pm 0.5(3.5-5)$ & $\begin{array}{c}7.5 \\
\text { Sometimes a } \\
\text { narrow gap }\end{array}$ & $\begin{array}{c}9.9 \\
\text { Sometimes a } \\
\text { narrow gap }\end{array}$ & $\begin{array}{l}12.7 \pm 3.1(6.9-18.5) \\
\quad \text { (continous) }\end{array}$ \\
\hline Length of PM2 & $8.1 \pm 7.9(4.4-10.2)$ & $5.9 \pm 1.2(2.2-7.8)$ & $6.25 \pm 1.6(4.6-7.9)$ & $6.0 \pm 1.0(4.5-8)$ & - & - & - \\
\hline Length M1 & $1.2 \pm 0.4(0.9-1.5)$ & $1.6 \pm 0.3(0.9-1.8)$ & $2.0 \pm 1.2(2.0-2.9)$ & $2.3 \pm 0.3(2-3)$ & 2.6 & 3 & $2.75 \pm 0.7(1.4-3.8)$ \\
\hline Length M2 & $1.6 \pm 0.3(1.2-2.1)$ & $1.8 \pm 0.4(1.2-2.4)$ & $3.1 \pm 1.8(2.7-3.5)$ & $2.9 \pm 0.4(2-4)$ & 2.8 & 3.6 & $3.5-0.9(1.3-4.9)$ \\
\hline Length M3 & $0.5 \pm 0.2(0.2-0.9)$ & $0.4 \pm 0.1(0.3-0.7)$ & $0.8 \pm 0.5(0.7-1.0)$ & $1.8 \pm 0.3(1.2-2.1)$ & 1.1 & 1 & $1.5 \pm 0.4(0.6-2.3)$ \\
\hline Buccal field/Body legth & $0.4 \pm 0.1(0.3-0.5)$ & $0.4 \pm 0.1(0.3-0.5)$ & $0.4 \pm 0.1(0.4-0,5)$ & - & 0.4 & 0.4 & $0.4 \pm 0.1(0.35-0.55)$ \\
\hline Position of CVP & $\begin{array}{l}\text { Posterior end } \\
\text { of kinety } 2\end{array}$ & $\begin{array}{l}\text { Posterior end } \\
\text { of kinety } 2\end{array}$ & $\begin{array}{l}\text { Posterior end } \\
\text { of kinety } 2\end{array}$ & Between kinety 1 \& 2 & $\begin{array}{r}\text { Poste } \\
\text { of kinety } 2 \text { (ocas } \\
\text { the base of } k\end{array}$ & $\begin{array}{l}\text { or end } \\
\text { onally } 2 \text { CVP's at } \\
\text { ety } 2 \text { and 3) }\end{array}$ & $\begin{array}{l}\text { Posterior } \\
\text { end of kinety } 2\end{array}$ \\
\hline Characteristics of Kn & Terminate at M1 & Terminate at M1 & Terminate at M1 & Terminate at M1 & Termin & e at M1 & Terminate at M1 \\
\hline Sample location & Huarmey, Perú & Huarmey, Perú & Galicia, Spain & Montpellier, France & Miam & U.S.A. & Miami, USA \\
\hline Host & Paralichthys adspersus & Paralichthys adspersus & Scophthalmus maximus & Dicentrarchus labrax & $\begin{array}{r}\text { Sea hor } \\
\text { bay waters of }\end{array}$ & $\begin{array}{l}\text { s?-local } \\
\text { liami, Florida- }\end{array}$ & Sea horses \\
\hline Life cycle & Microstome/tomite & Microstome/tomite & Microstome/tomite & - & & & Macrostome/microstome/tomite \\
\hline Data source & Present study & Present study & Present study & Dragesco et al. (1995) & Thompson \& & oewus (1964) & Present study \\
\hline
\end{tabular}




$\begin{array}{cccccc}\begin{array}{c}\text { M. avidus } \\ \text { strain } \mathrm{Ma} / 2\end{array} & \begin{array}{c}\boldsymbol{P} \text {. dicentrarchi } \\ \text { isolate } \mathrm{Pe} 5\end{array} & \begin{array}{c}\boldsymbol{P} \text {. dicentrarchi } \\ \text { isolate } \mathrm{Pe} 7\end{array} & \begin{array}{c}\boldsymbol{P} \text {. dicentrarchi } \\ \text { strain I1 }\end{array} & \begin{array}{c}\text { M. avidus } \\ \text { strain YK2 }\end{array} & \begin{array}{c}\boldsymbol{P} \text {. armatalis strain } \\ \text { GF2008082801 }\end{array}\end{array}$

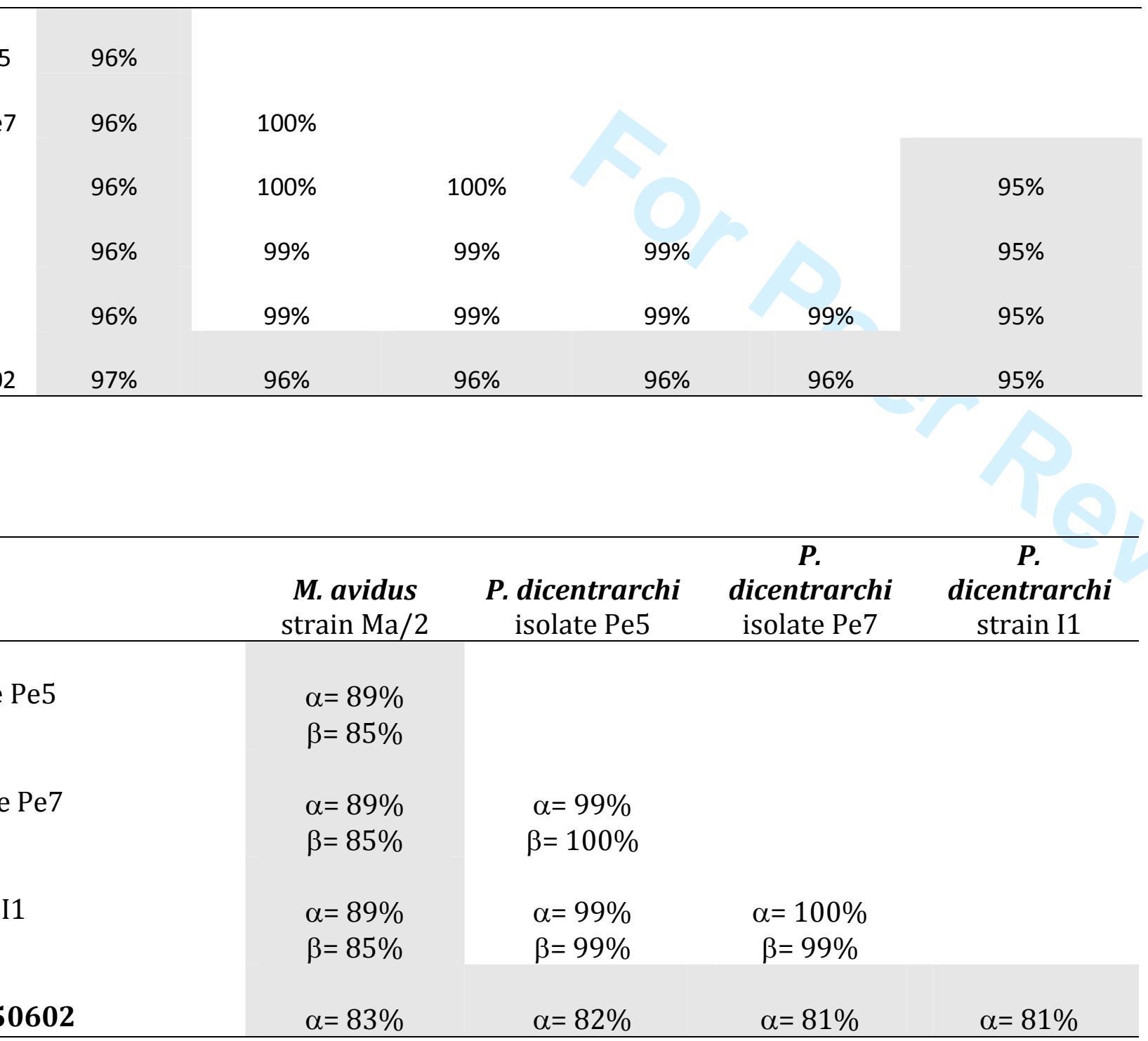




\section{Supplementary Material: nucleotide sequences used}

\begin{tabular}{|c|c|c|c|c|c|}
\hline Specie & strain & gene & $\begin{array}{c}\text { Accession } \\
\text { number }\end{array}$ & Nucleotide sequence & $\begin{array}{c}\text { Length } \\
\text { (bp) }\end{array}$ \\
\hline $\begin{array}{c}\text { Philasterides } \\
\text { dicentrarchi }\end{array}$ & 11 & $\begin{array}{l}\text { 18S ribosomal } \\
\text { RNA gene, } \\
\text { complete } \\
\text { sequence }\end{array}$ & JX914665.1 & $\begin{array}{l}\text { AATCTGGTTGATCCTGCCAGTAGTCATATGCTTGTCTCAAAGATTAAGCCATGCATGTCTAAGTATAAATAGGTATACAGTGAAACT } \\
\text { GCGAATGGCTCATTAAAACAGTTATAGTTTATTTGATAATGGAAAGCTACATGGATAACCGTGGTAATTCTAGAGCTAATACATGC } \\
\text { TGTCAAACCCGACCTTTGGAAGGGTTGTATTATTAGATATTAAGCCAATATTCCTTCGGGTCTATTGTGGTGAATCATAGTAACT } \\
\text { GATCGAATCTCTTCACGAGATAAATCATTCAAGTTTCTGCCCTATCAGCTTTCGATGGTAGTGTATTGGACTACCATGGCAGTCAC } \\
\text { GGGTAACGGAGAATTAGGGTTCGGTTCCGGAGAGGGAGCCTGAGAAACGGCTACCACATCTAAGGAAGGCAGCAGGCGCGTA } \\
\text { AATTACCCAATCCTGATTCAGGGAGGTAGTGACAAGAAATAACAACCTGGGGCCTCACGGCCTTACGGGATTGTAATGAGAAC } \\
\text { AATTTAAACGACTTAACGAGGAACAATTGGAGGGCAAGTCTGGTGCCAGCAGCCGCGGTAATTCCAGCTCCAATAGCGTATATT } \\
\text { AAAGTTGTTGCAGTTAAAAAGCTCGTAGTTGAACTTCTGCATGTGCCCAGTTCTGGCTTCGGTCAAGCTGTGGTGTATGCATCCG } \\
\text { CTTGCAAAGCTAGACCGGTCTTCATTGATCGACTAGTGGAGTAGGCTCTTTACCTTGAAAAATTAGAGTGTTCAGGCAGGCAA } \\
\text { TGGCTCGAATACATTAGCATGGAATAATGGAATAGGACTTTTGTCCATTTGGTTGGTTATTGGACATAAGTAATGATTAAAAGGGA } \\
\text { CAGTTGGGGGATTAGTATTTAATTGTCAGAGGTGAAATCTTGGATTTATTAAAGACTAACTTATGCGAAAGCATTTGCCAAGGA } \\
\text { TGTTTTCATTAATCAAGAACGAAAGTTAGGGGATCAAAGACGATCAGATACCGTCCTAGTCTTAACTATAAACTATACCGACTCGG } \\
\text { AATCGGACCGGCTTATAAAACTGGTTCGGCGCGTATGAGAAATCAAAGTCTTTGGTTCTGGGGGAGTATGGTCGCAAGGCT } \\
\text { GAAACTTAAAGGAATTGACGGAAGGGACCACCAGGCGTGGAGCCTGCGGCTTAATTTGACTCAACACGGGGAACTTACCAG } \\
\text { GTCCAAACATGGGTGGGATTGACAGATTGAGAGCTCTTTCTTGATTCTATGGGTGGTGGTGCATGGCCGTTCTTAGTTGGTGGA } \\
\text { GTGATTTGTCTGGTTAATTCCGTTAACGAACGAGACCTTAACCTGCTAAATAGTACGTTGATGCACAATTGGCGTTACTTCTTAGA } \\
\text { GGGACTATGCGCTTTGAAACGCATGGAAGTTGAGGCAATAACAGGTCTGTGATGCCCTTAGATGTCCTGGGCCGCACGCGCG } \\
\text { CTACAATGACTCGCTCAGAAAGTACTTCCTGGTCCGGAAGGATTCGGGTAATCTTTTAAATACGAGTCGTGTTAGGGATCGATCT } \\
\text { TTGTAATTATGGATCTTGAACGAGGAATGCCTAGTAAGTGCAAGTCATCAGCTTGTACTGATTACGTCCCTGCCCTTTGTACACA } \\
\text { CCGCCCGTCGCTCCTACCGATTTCGAGTGATCCGGTGAACCTTCTGGACTGAGCACGCTTGCGTGAACGGGAAGTTAAGTAAAC } \\
\text { CTAATCACTTAGAGGAAGGAGAAGTCGTAACAAGGTTTCCGTAGGTGAACCTGCGGAAGGATC }\end{array}$ & 1759 \\
\hline $\begin{array}{c}\text { Miamiensis } \\
\text { avidus ATCC }{ }^{\circledR} \\
50180^{\text {TM }}\end{array}$ & $\mathrm{Ma} / 2$ & $\begin{array}{l}\text { 18S ribosomal } \\
\text { RNA gene, } \\
\text { complete } \\
\text { sequence }\end{array}$ & KX357144 & 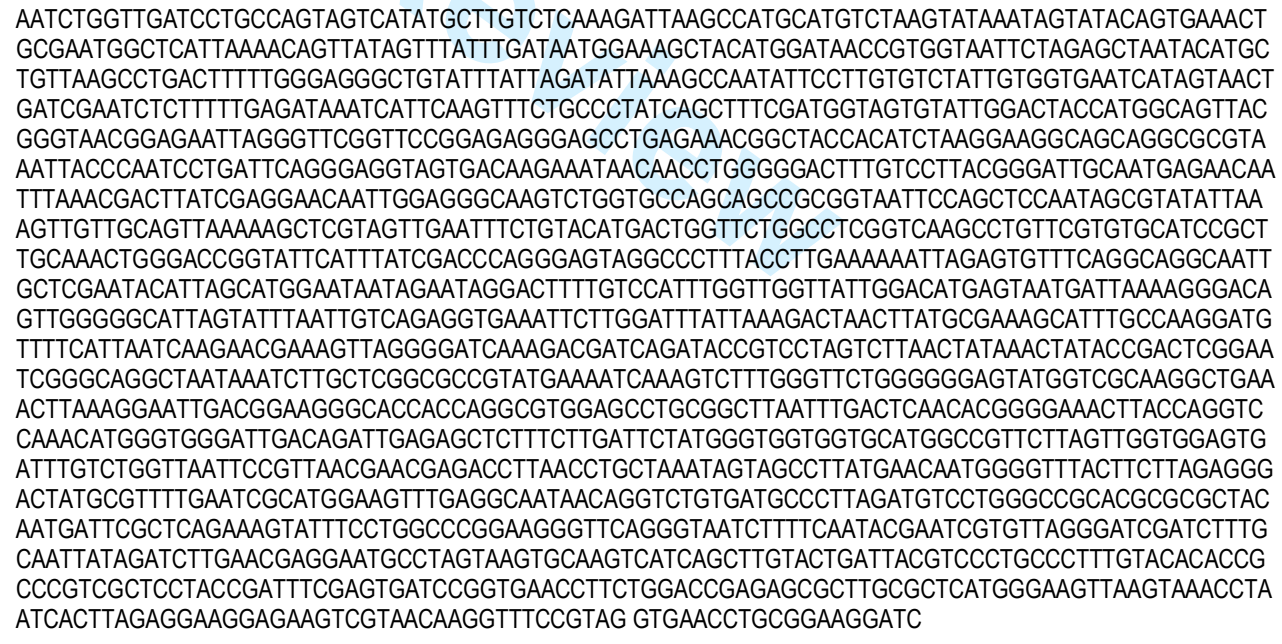 & 1759 \\
\hline Isolates Pe5 & - & $18 \mathrm{~S}$ ribosomal & - & $\begin{array}{l}\text { AATCTGGTTGATCCTGCCAGTAGTCATATGCTTGTCTCAAAGATTAAGCCATGCATGTCTAAGTATAAATAGTATACAGTGAAACT } \\
\text { GCGAATGGCTCATTAAAACAGTTATAGTTTATTTGATAATGGAAAGCTACATGGATAACCGTGGTAATTCTAGAGCTAATACATGC }\end{array}$ & 1759 \\
\hline
\end{tabular}




\begin{tabular}{|c|c|c|c|c|c|}
\hline and Pe7 & & $\begin{array}{l}\text { RNA gene, } \\
\text { complete } \\
\text { sequence }\end{array}$ & & 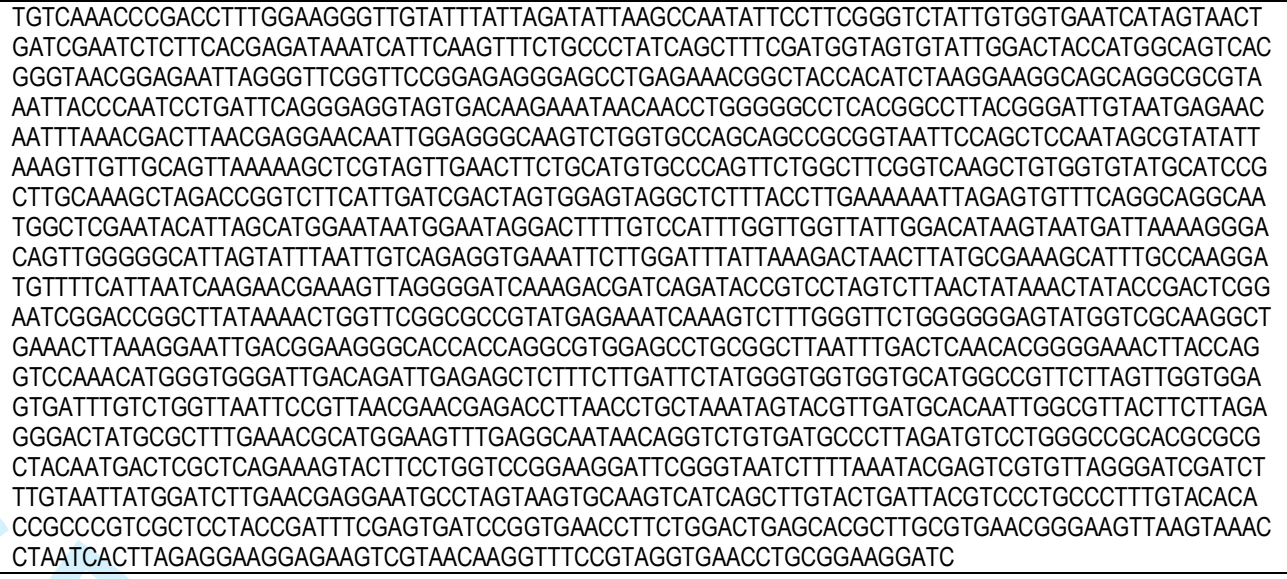 & \\
\hline $\begin{array}{l}\text { Philasterides } \\
\text { dicentrarchi }\end{array}$ & 11 & $\begin{array}{c}\text { Alpha } \\
\text { tubulin, } \\
\text { partial } \\
\text { sequence }\end{array}$ & KX357145 & $\begin{array}{l}\text { TCTTAGATTTAGAACCCACCGTTATTGATGAAGTCAGAACCGGAACTTACAGACAATTATTCCACCCCGAACAATTAATCTCCGGA } \\
\text { AAAGAAGATGCCGCTAACAACTTCGCCAGAGGACACTACACCATCGGAAAAGAAATCGTTGATTTATGCTTAGACAGAATCAGAA } \\
\text { AATTAGCTGACAACTGTACCGGACTC }\end{array}$ & 197 \\
\hline $\begin{array}{l}\text { Miamiensis } \\
\text { avidus ATCC }{ }^{\circledR} \\
50180^{\mathrm{TM}}\end{array}$ & $\mathrm{Ma} / 2$ & $\begin{array}{c}\text { Alpha } \\
\text { tubulin, } \\
\text { partial } \\
\text { sequence }\end{array}$ & KX357143 & $\begin{array}{l}\text { TCTTAGATCTCGAACCCACCGTTATCGATGAAGTTAGAACCGGAACTTATAGACAACTCTTCCACCCCGAATAATTGATCTCCGG } \\
\text { AAAAGAAGATGCCGCCAACAACTTCGCCAGAGGACATTACACTATCGGAAAAGAAATCGTTGACCTTTGTCTCGATAGAATTAGA } \\
\text { AAACTCGCTGACAACTGTACCGGATCT }\end{array}$ & 197 \\
\hline Isolate Pe5 & - & $\begin{array}{c}\text { Alpha } \\
\text { tubulin, } \\
\text { partial } \\
\text { sequence }\end{array}$ & - & $\begin{array}{l}\text { TCTTAGATTTGGAACCCACCGTTATTGATGAAGTCAGAACCGGAACTTACAGACAATTATTCCACCCCGAACAATTAATCTCCGG } \\
\text { AAAAGAAGATGCCGCTAACAACTTCGCCAGAGGACACTACACCATCGGAAAAGAAATCGTTGATTTATGCTTAGACAGAATCAGA } \\
\text { AAATTAGCTGACAACTGTACCGGACTC }\end{array}$ & 197 \\
\hline Isolate Pe7 & - & $\begin{array}{c}\text { Alpha } \\
\text { tubulin, } \\
\text { partial } \\
\text { sequence }\end{array}$ & - & $\begin{array}{l}\text { TCTTAGATTTAGAACCCACCGTTATTGATGAAGTCAGAACCGGAACTTACAGACAATTATTCCACCCCGAACAATTAATCTCCGGA } \\
\text { AAAGAAGATGCCGCTAACAACTTCGCCAGAGGACACTACACCATCGGAAAAGAAATCGTTGATTTATGCTTAGACAGAATCAGAA } \\
\text { AATTAGCTGACAACTGTACCGGACTC }\end{array}$ & 197 \\
\hline $\begin{array}{c}\text { Philasterides } \\
\text { dicentrarchi }\end{array}$ & 11 & $\begin{array}{l}\text { Beta } \\
\text { tubulin, }\end{array}$ & CQ342956.1 & $\begin{array}{l}\text { CCATAATTCTGTCGGGGTATTCTTCTCTGACTTTGGAGATCAATAAGGTTCCCATTCCGGATCCAGTTCCTCCTCCTAAAGAGTG } \\
\text { GGTGATTTAGAATCCTTATAAGCAATCACATCCTTCAGCTTCTTTTCTGACAACATCTAAAACAGAGTCGATTAATTCAGCTCCTTC } \\
\text { GGTGTAGTGTCCTTTGGCCCAGTtGTTACCGGCTCCGGTTATCCGAAAACGTATTAATTATTTAATTTTAATTACATTCTTTCTT } \\
\text { CAATATATAAAACAATTATGAATTATTTTTTATTAATTATTACAAGTTATCAGGTCTGAAGAGTTGTCCGAAAGGTCCAGCTCTAAC }\end{array}$ & 388 \\
\hline
\end{tabular}




\begin{tabular}{|c|c|c|c|c|c|}
\hline & & $\begin{array}{c}\text { partial } \\
\text { sequence }\end{array}$ & & GGAATCCATGGTACCGGGTTCCAAATCCATAAGGATGGCTC & \\
\hline $\begin{array}{l}\text { Miamiensis } \\
\text { avidus } \text { ATCC }^{\circledR} \\
50180^{\text {TM }}\end{array}$ & $\mathrm{Ma} / 2$ & $\begin{array}{l}\text { Beta } \\
\text { tubulin, } \\
\text { partial } \\
\text { sequence }\end{array}$ & KX357147 & $\begin{array}{l}\text { CCATAATTCTGTCGGGGTATTCTTCTCTGACTTTGGAGATAAGGAGGGTACCCATTCCGGATCCAGTTCCTCCTCCAAGAGAGTG } \\
\text { GGTGATTTAGAAACCTTATAAGCAATCACATCCTTCGGCTTCTTTTCTGACGACATCCAAAACGGAGTCGATCAATTCAGCTCCTT } \\
\text { CGGTGTAATGACCTTTGGCCCAGTTGTTACCAGCTCCAGTTTGTCCGAAAACGCTATTATAAAATAAAATTAATATTTTCTCAGTTT } \\
\text { TTAATATATTTCAATGTGTATTTACAAGTTATCGGGTCTGAAGAGTTGACCGAAAGGTCCAGCTCTTACGGAATCCATGGTTCCGG } \\
\text { GTTCGAGATCCATTAAGATGGCTCTGGGACGTATCTTCCTCCG }\end{array}$ & 388 \\
\hline Pe5 isolate & - & $\begin{array}{l}\text { Beta } \\
\text { tubulin, } \\
\text { partial } \\
\text { sequence }\end{array}$ & - & $\begin{array}{l}\text { CCATAATTCTGTCGGGGTATTCTTCTCTGACTTTGGAGATCAATAAGGTTCCCATTCCGGATCCAGTTCCTCCTCCTAAAGAGTG } \\
\text { GGTGATTTAGAATCCTTATAAGCAATCACATCCTTCAGCTTCTTTTCTGACAACATCTAAAACAGAGTCGATTAATTCAGCTCCTTC } \\
\text { GGTGTAGTGTCCTTTGGCCCAGTTGTTACCGGCTCCGGTTATCCGAAAACGCTATTTAATTATTTAATTTTAATTACATTCTTTCT } \\
\text { TCATTATATAAAACAATTATGAATTATTTTTTATTAATTATTACAAGTTATCAGGTCTGAAGAGTTGTCCGAAAGGTCCAGCTCTAAC } \\
\text { GGAATCCATGGTACCGGGTTCCAAATCCATAAGGATGGCTC }\end{array}$ & 388 \\
\hline Pe7 isolate & - & $\begin{array}{l}\text { Beta } \\
\text { tubulin, } \\
\text { partial } \\
\text { sequence }\end{array}$ & - & $\begin{array}{l}\text { CCATAATTCTGTCGGGGTATTCTTCTCTGACTTTGGAGATCAATAAGGTTCCCATTCCGGATCCAGTTCCTCCTCCTAAAGAGTG } \\
\text { GGTGATTTAGAATCCTTATAAGCAATCACATCCTTCAGCTTCTTTTCTGACAACATCTAAAACAGAGTCGATTAATTCAGCTCCTTC } \\
\text { GGTGTAGTGTCCTTTGGCCCAGTTGTTACCGGTCCGGTTATCCGAAAACGCTATTTAATTATTTAATTTTAATTACATTCTTTCT } \\
\text { TCATTATATAAAACAATTATGAATTATTTTTTATTAATTATTACAAGTTATCAGGTCTGAAGAGTTGTCCGAAAGGTCCAGCTCTAAC } \\
\text { GGAATCCATGGTACCGGGTTCCAAATCCATAAGGATGGCTC }\end{array}$ & 388 \\
\hline
\end{tabular}

